\title{
Review
}

\section{Amsterdam Dementia Cohort: Performing Research to Optimize Care}

\author{
Wiesje M. van der Flier ${ }^{\mathrm{a}, \mathrm{b}, *}$ and Philip Scheltens ${ }^{\mathrm{a}}$ \\ ${ }^{\mathrm{a}}$ Department of Neurology, Alzheimer Center, VU University Medical Center, Amsterdam Neuroscience, \\ Amsterdam, The Netherlands \\ ${ }^{\mathrm{b}}$ Department of Epidemiology and Biostatistics, VU University Medical Center, Amsterdam, The Netherlands
}

Accepted 4 December 2017

\begin{abstract}
The Alzheimer center of the VU University Medical Center opened in 2000 and was initiated to combine both patient care and research. Together, to date, all patients forming the Amsterdam Dementia Cohort number almost 6,000 individuals. In this cohort profile, we provide an overview of the results produced based on the Amsterdam Dementia Cohort. We describe the main results over the years in each of these research lines: 1) early diagnosis, 2) heterogeneity, and 3) vascular factors. Among the most important research efforts that have also impacted patients' lives and/or the research field, we count the development of novel, easy to use diagnostic measures such as visual rating scales for MRI and the Amsterdam IADL Questionnaire, insight in different subgroups of AD, and findings on incidence and clinical sequelae of microbleeds. Finally, we describe in the outlook how our research endeavors have improved the lives of our patients.
\end{abstract}

Keywords: Alzheimer's disease, Amsterdam Dementia Cohort, dementia, diagnosis, heterogeneity, mild cognitive impairment, prognosis, vascular factors

\section{BACKGROUND}

The Alzheimer center of the VU University Medical Center (VUmc) opened in 2000 and combines both patient care and research. Since its founding, it has been directed by Professor Philip Scheltens. When the center opened its doors in 2000, the Alzheimer world looked entirely different than now. Neuroimaging, notably MRI, had only been recently introduced, enabling visualization of atrophy and vascular pathology in greater detail [1]. Diagnosis was entirely based on clinical criteria and a definite diagnosis could only be made postmortem [2]. The field became aware that Alzheimer's disease (AD) develops gradually, and the concept of mild cogni-

\footnotetext{
${ }^{*}$ Correspondence to: Wiesje M. van der Flier, Alzheimer Center, Room PK - 1 Z 44, VU University Medical Center, de Boelelaan 1118, 1081 HZ Amsterdam, The Netherlands. Tel.: +31 020 4440816; Fax: +31 020 4440715; E-mail: wm.vdflier@vumc.nl.
}

tive impairment $(\mathrm{MCI})$ as a transitional or at risk stage had recently been introduced [3]. This was the time when the first (and still only available) drugs like the cholinesterase inhibitors and memantine had been approved and were used globally. This was also the time that with the development of cerebrospinal fluid (CSF) biomarkers, in vivo measurement of amyloid- $\beta$ $(\mathrm{A} \beta)$ and tau was finally becoming a reality, a reality which would deeply affect the field.

At the VUmc Alzheimer center, patient care and research have always gone hand in hand. And this founding principle is still at the core of our existence. We perform all investigations necessary for a diagnostic workup of dementia in one day. Each week, we see 12 patients in three so-called screeningdays. The diagnostic workup includes medical and neurological investigation by a neurologist, assessment of vital functions, informant based history and assessment of needs by a specialized dementia nurse, 
Table 1

Standardized clinical workup, rating scales, and cognitive test battery

\begin{tabular}{|c|c|c|}
\hline Category & Domain & Name of test or questionnaire \\
\hline \multirow[t]{6}{*}{ Clinical evaluation } & Anamnesis & Anamnesis, evaluation of complaints \\
\hline & & Medical history \\
\hline & & Family history \\
\hline & & Alcohol intake, smoking, drugs \\
\hline & Physical & Weight, height, waist \\
\hline & measurements & Blood pressure \\
\hline \multirow[t]{17}{*}{ Cognitive tests } & Global cognition & Mini-Mental State Examination \\
\hline & Memory & Visual association task (VAT) \\
\hline & & $\begin{array}{l}\text { Dutch version of the Rey Auditory Verbal } \\
\text { Learning Test (RAVLT) }\end{array}$ \\
\hline & Attention & Digit span forward \\
\hline & & Trail Making Test (TMT) A \\
\hline & & Stroop colour word test I and II \\
\hline & Executive & Trail Making Test (TMT) B \\
\hline & functioning & Digit span backwards \\
\hline & & Stroop colour-word test III \\
\hline & & Frontal Assessment Battery (FAB) \\
\hline & & Letter Fluency Test (version D-A-T) \\
\hline & Language & Category fluency animals \\
\hline & & Visual association test - 'naming' \\
\hline & $\begin{array}{l}\text { Visuo-spatial } \\
\text { functioning }\end{array}$ & $\begin{array}{l}\text { Fragmented letters (VOSP: Visual Objective } \\
\text { and Space Perception) }\end{array}$ \\
\hline & & Number location (VOSP) \\
\hline & & Dot Counting (VOSP) \\
\hline & & Rey Complex Figure Copy task \\
\hline Activities of daily living & IADL & Amsterdam IADL questionnaire \\
\hline \multirow[t]{2}{*}{ Behavioral and psychological } & $\begin{array}{c}\text { Behavioral } \\
\text { changes }\end{array}$ & Neuropsychiatric Inventory (NPI) \\
\hline & $\begin{array}{l}\text { Depressive } \\
\text { symptoms }\end{array}$ & Geriatric Depression Scale \\
\hline
\end{tabular}

neuropsychological investigation, brain magnetic resonance imaging (MRI), electroencephalogram (EEG), standard labs and lumbar puncture (see Table 1 for overview of rating scales and cognitive test battery). In addition, we ask all patients for informed consent to store their clinical data in a database with the goal to use these data to answer research questions and for the storage of biomaterial (blood (serum/plasma), DNA, CSF) in our biobank. We see many of our patients on an annual basis and have tailored follow up programs for subjects with subjective cognitive decline (SCD), MCI and patients with $\mathrm{AD}$, frontotemporal dementia (FTD), and dementia with Lewy bodies (DLB), consisting of medical examination, neuropsychological tests, and care interview. As neuropathology is a hugely important source of information, we collaborate with the Dutch Brain Bank and discuss the possibility of brain donation with our patients. The local Medical Ethics Committee has approved a general protocol for biobanking and using the clinical data for research purposes. Together, all these patients form the Amsterdam Dementia Cohort, which includes
Table 2

Demographic characteristics of Amsterdam Dementia Cohort

\begin{tabular}{lc}
\hline & 2017 \\
\hline $\mathrm{N}$ & 5,960 \\
Gender, $\mathrm{F}$ & $2,586(43 \%)$ \\
Age, years & $64 \pm 10$ \\
Age, $\leq 65$ years & $3,354(56 \%)$ \\
MMSE & $24 \pm 5$ \\
Availability: & \\
MRI & $4,565(77 \%)$ \\
EEG & $4,969(83 \%)$ \\
Biomaterial (CSF, blood, DNA) & $4,137(69 \%)$ \\
APOE status & $5,242(88 \%)$ \\
\hline
\end{tabular}

Data are represented as mean \pm standard deviation or $\mathrm{n}(\%)$. The Amsterdam Dementia Cohort is the ongoing study attached to the memory clinic of the VUmc Alzheimer center. Numbers presented were derived from the database in September 2017.

to date almost 6,000 individuals (Table 2; Fig. 1). The associated biobank includes material from over 4,000 individuals. The Amsterdam Dementia Cohort, which is a heterogeneous and ongoing, clinically based, memory clinic cohort, has been at the basis of much of the research output of the VUmc Alzheimer center [4]. 

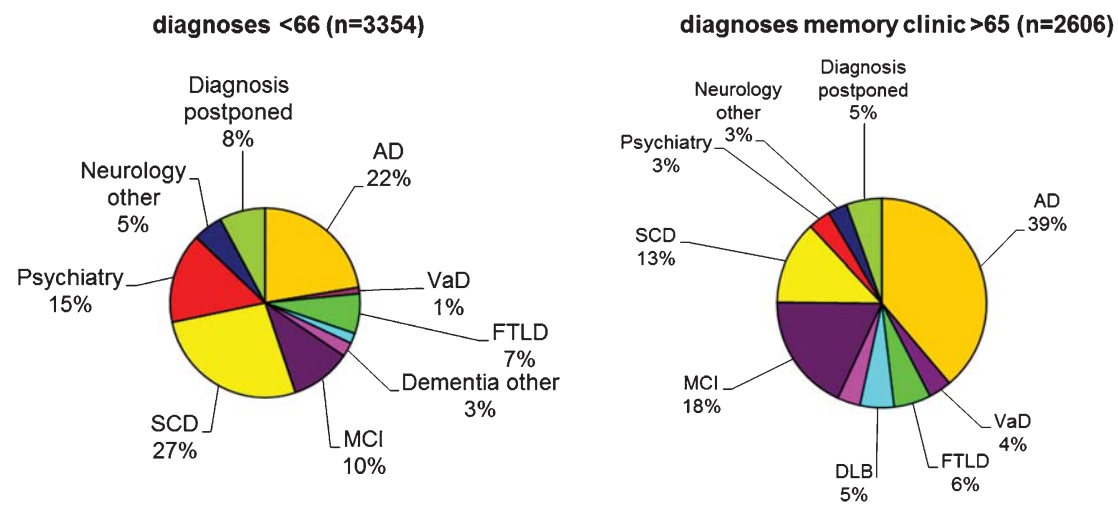

Fig. 1. The pie charts show initial diagnoses in the Amsterdam Dementia Cohort, according to age-at-onset. The pie charts are based on 5,960 patients who formed the Amsterdam Dementia cohort in September 2017. At younger age, the most frequent diagnosis is SCD, followed by $\mathrm{AD}$. In the older age group, $\mathrm{AD}$ and $\mathrm{MCI}$ are the two most frequent diagnoses. Due to the relatively young age of the patients visiting our center, more rare diagnoses such as frontotemporal dementia are relatively frequent. AD, probable and possible Alzheimer's disease; VaD, vascular dementia; FTLD, frontotemporal lobar degeneration, includes both behavioral variant FTD and primary progressive aphasia; DLB, dementia with Lewy bodies; Dementia other include other types of dementia such as Creutzfeldt-Jakob disease, corticobasal degeneration, progressive supranuclear palsy, and alcohol dementia; MCI, mild cognitive impairment.

In 2000, the main questions in the field were: how can we make an early and reliable diagnosis (in fact: how can we determine the presence of AD pathology in vivo)? In addition, there was a lot of interest in the joint observation of neurodegenerative and vascular disease, which, though commonly observed, was still not explained. Finally, we were really interested in the remarkable clinical manifestations that we sometimes observed, particularly in younger patients. Was something going on in these specific subgroups? Due to the set-up of the Amsterdam Dementia Cohort, research efforts of the VUmc Alzheimer center have a firm basis in clinical challenges. Our four main research lines are the following: 1) Early diagnosis. We attempt to find novel methods to make an accurate and early diagnosis of $\mathrm{AD}$ and other types of dementia. In this research line, we also position the studies into MCI and SCD, which represent the shift forward in the field, to increasingly early disease stages. 2) Heterogeneity in clinical manifestation. In this line, we take differences among individuals as a starting point to understand underlying and multiple biological mechanisms that may contribute to clinical disease. In this research, we position interindividual differences within the spectrum of $\mathrm{AD}$, as well as different types of dementia, particularly frontotemporal lobar degeneration (FTLD) and DLB. (3) Vascular factors. This research focuses on the vascular comorbidity that is often observed in patients with $\mathrm{AD}$ and also encompasses studies in vascular cognitive impairment. (4) Interventions. To date, there is no cure for $\mathrm{AD}$ or any other type of dementia.
Our ultimate goal is to find a therapy to cure or at least halt the neurodegenerative process behind many of the dementias. Our observational studies are based on the notion that the key to finding therapy lies in a better understanding of the mechanisms leading to $\mathrm{AD}$ and other dementias. Studies on pharmacological treatment are usually initiated and facilitated by big pharma. The VUmc Alzheimer center has spun-out to the Brain Research Center (http://www.brainresearchcenter.nl), where we organize our participation in commercial clinical trials. In doing so, we have gained a lot of expertise, and we are asked to act as PI and provide consultancy on trial design on a regular basis. Our own investigatorinitiated intervention studies are mostly restricted to lifestyle interventions. In the context of this cohort profile, we restrict our description to observational studies (i.e., first three research lines).

Starting in 2000, and working our way through the first two decades of the 21st millennium, the field has seen a lot of new insights and development [5]. The Amsterdam Dementia Cohort has turned out to be very fruitful in answering clinically relevant questions (Fig. 2). As a natural consequence of our set-up, (almost) all patients contribute to research by providing their clinical data. The research questions we answer, consequently have important clinical relevance. With the research results we aim to further improve our patient care. Examples of this translational cycle are the development of MRI rating scales for medial temporal lobe atrophy and posterior cortical atrophy (PCA), which are now used on a regular 


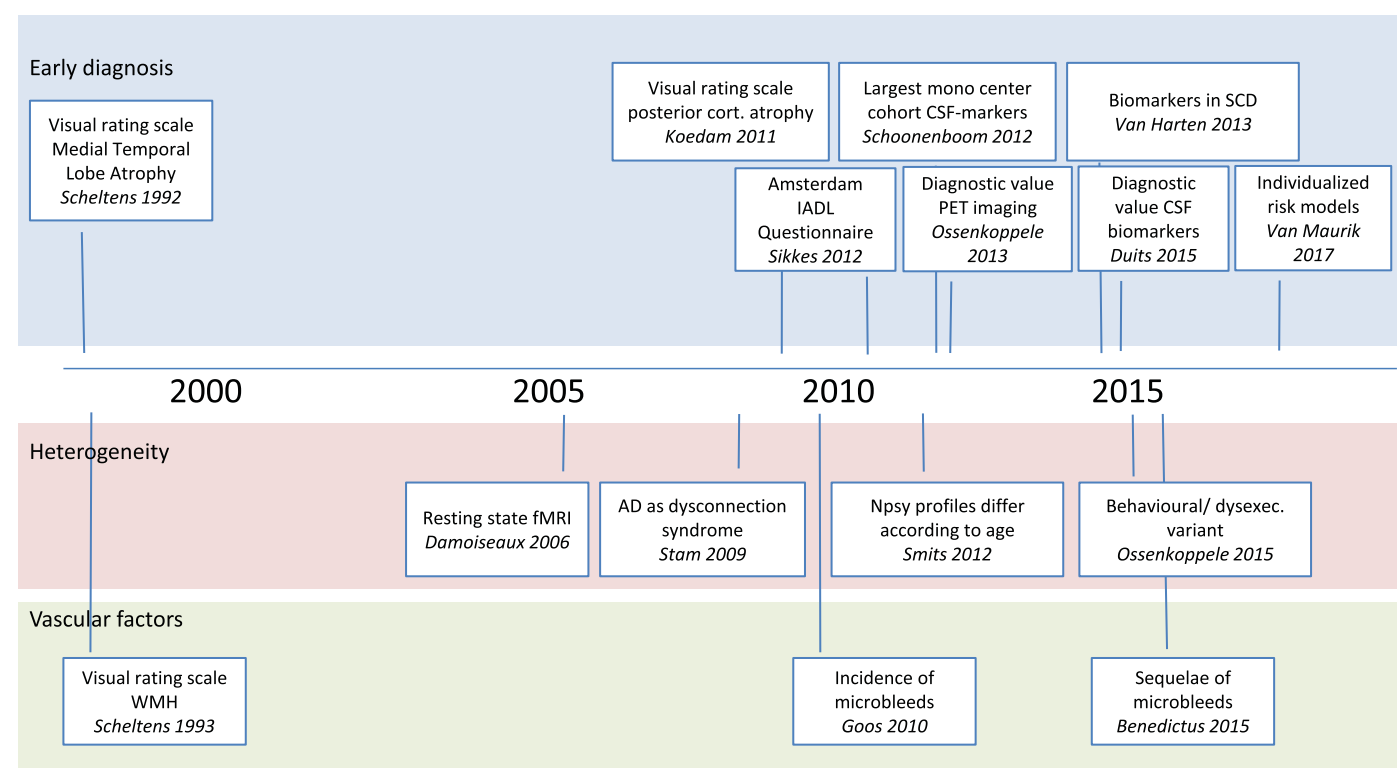

Fig. 2. Timeline displaying some of the most important papers based on the Amsterdam Dementia Cohort. Well before the official start of the Amsterdam Dementia Cohort, two papers on visual rating scales have proved very impactful. In later years, we have developed a third visual rating scale and the Amsterdam IADL questionnaire. More recently, we have performed a series of studies on diagnostic value of both CSF biomarkers and PET. Our study on CSF biomarkers in patients with Subjective Cognitive Decline was among the first to show the relevance of these markers in cognitively healthy individuals. In the part on heterogeneity of disease, we also displayed two seminal papers on resting state connectivity, and viewing $\mathrm{AD}$ as a disconnection syndrome. More recently, we described differences between subgroups of patients in cognitive and clinical profile. In the research line vascular factors, our studies on microbleeds have contributed to the field at the same time when interest in amyloid related imaging abnormalities swiftly became a topic of interest due to their frequent occurrence in anti-amyloid trials.

basis in both clinical and trial settings, the observation of microbleeds on MRIs of our patients, which now have important relevance in the setting of antiamyloid clinical trials, and the Amsterdam IADL questionnaire, which we developed through a process of co-creation with patients and professionals. The questionnaire better reflects activities of daily living anno 2017, and therefore use of this scale is a huge improvement in diagnosis of dementia.

In this cohort profile, we provide an overview of the results produced using data from the Amsterdam Dementia Cohort. We follow the structure of our research lines and describe the main results over the years, ending each part with a wrap up describing what has been achieved, and which are the open questions we are working on. Finally, we describe in the outlook whether and how our research endeavors have improved the lives of our patients.

\section{EARLY DIAGNOSIS}

\section{MRI}

The Amsterdam Dementia Cohort has a long tradition of neuroimaging research. In the nineties of the last century, even before the official start of the VUmc Alzheimer center, Scheltens developed a visual rating scale for atrophy of the medial temporal lobe (MTA) [6, 7]. This was a major step forward, as this easy to use visual rating scale performed comparably to time- and labor-intensive approaches of volumetric measurements of brain structures such as the hippocampus. Over the years, the MTA-or the Scheltens scale as it became known-has gained wide acceptance, both in observational studies and in clinical trials. Following our observation of atrophy in the posterior parts of the brain, we developed, together with colleagues from University College London (UCL), a similar visual rating scale to rate PCA $[8,9]$. In the largest series to date, we visualized how age and AD diagnosis independently affect MTA score (additive effects) [10, 11]. By contrast, PCA is specifically associated with $\mathrm{AD}$ diagnosis, while age hardly has any effect. When we evaluated a large group of patients with AD we frequently observed not only MTA, but also PCA in our relatively young group of $\mathrm{AD}$ patients [12]. Again, in a collaborative study with UCL comparing a number of visual rating scales to postmortem verified diagnoses in the 
ADC and UCL cohorts, the MTA scale was the best performing scale in diagnosing AD [13].

It is increasingly recognized that atrophy does not occur strictly localized, but globally, in patterns. Global atrophy discriminates patients from controls as well. Using voxel-based morphometry (VBM), we showed that the pattern of atrophy in patients with early onset $\mathrm{AD}$ is more widespread, while in older patients, atrophy is generally more restricted to the medial temporal lobe $[14,15]$. Both visual rating of MTA and patterns of atrophy as estimated using VBM are helpful to predict progression to dementia in patients with MCI [16-20]. In addition, other quantitative MRI techniques, such as diffusion tensor imaging, resting state functional MRI (rs-fMRI) and arterial spin labeling (ASL) were associated with increased risk of progression to dementia [20-24]. These techniques also proved useful to distinguish different types of dementia, although sensitivity and specificity are far from perfect [25-29]. Extracting imaging information from different modalities and combining these data may improve diagnostic performance [27, 30, 31].

Taking the viewpoint that all neurons operate in concert, rather than specific brain locations being responsible for specific tasks, it is useful to evaluate the grey matter with a network approach. Using a graph theoretical framework, we found that grey matter based network measures add diagnostic value to simple measures of atrophy and have strong relations with cognitive impairment [32-34].

In addition to its diagnostic use, MRI is useful to track changes in the disease course over time. Rate of atrophy increases with the course of the disease, is related with type of dementia, and with rate of cognitive decline $[17,28,35]$. Rate of hippocampal atrophy seems to be more predictive of incipient AD dementia than whole brain atrophy [18]. These findings render MRI useful as a measure to monitor disease progression and for use as a surrogate outcome measure in trials [36].

\section{CSF biomarkers}

Around the turn of the millennium, assays to measure $A \beta_{1-42}$, total tau, and tau phosphorylated at threonine 181 (Ptau) in CSF were developed [37-39]. With this innovation, it became possible for the first time to measure the reflection of AD neuropathology in living patients. In the years to follow, we collected one of the largest monocenter biobanks worldwide and used these samples to develop the
CSF biomarkers as diagnostic markers which can be used in clinical practice. Over the years, we published cut-off values for each of the three biomarkers, and observed that especially in $A \beta$, there is an upward drift, with optimal cut-offs increasing from 550 to 700 over the years [40-42]. Using a ratio of $A \beta /$ tau has the advantage of combining both markers in one measure, appears to be robust for biomarker drift, as well as to inter-laboratory variation [43]. We confirmed good diagnostic accuracy, with a sensitivity of $94 \%$ and specificity of $71 \%$ when a tau/A $\beta$ ratio of 0.52 was used as cut-off $[40,43]$. One of the challenges in the use of CSF biomarkers is their harmonization, which particularly for $A \beta$ is a challenge [44]. As part of an international consortium, we published consensus guidelines to standardize pre-analytical variation and keep complication rate to a minimum [45]. In addition, we published a short movie to instruct local professionals how to perform a lumbar puncture [46].

As CSF biomarkers reflect ongoing AD pathology, they seem ideal candidates to track disease progression over time. We found that there is considerable variation in biomarker levels, both within and between samples, and therefore, when analyzing longitudinal samples, it is of importance to measure baseline and follow-up samples in one batch [47, 48]. Biomarker levels, particularly $\mathrm{A} \beta$, reach a plateau early in the disease. Longitudinally, we found that concentrations of all three markers increase over time, but the differences between groups are far larger than those within groups $[49,50]$. These three diseasespecific biomarkers have optimal diagnostic value, while other markers, such as neurofilament-light, isoprostanes, VILIP I, YLK-40, and Neurogranin, which are less specific to the disease, seem more sensitive for progression [50-52]. This illustrates optimal diagnostic biomarkers and prognostic biomarkers are not necessarily the same.

In our biobank, we collect paired CSF and blood samples. In a number of studies, we have attempted to replicate findings of mostly large epidemiological studies, or innovative panels of blood-based biomarkers based on highly selected patient groups, and repeatedly found that blood-based markers were not useful for diagnostic purposes [53-56]. Nonetheless, a blood-based biomarker or panel of biomarkers remains the holy grail of AD diagnosis. Such a bloodbased test could be used as a pre-screener in memory clinics or even in the primary care setting, when in the future, disease-modifying treatment becomes available. With the development of novel, highly sensitive assays, a new era seems to have arrived, 
where it may become possible to identify blood-based biomarkers.

\section{Positron emission tomography (PET)}

Among the most important discoveries of the past decades, is the development of amyloid-PET. More or less simultaneously, two tracers which claimed to selectively bind to amyloid were developed; Pittsburgh Compound-B $\left(\left[{ }^{11} \mathrm{C}\right] \mathrm{PIB}\right)$ and 2-(1-[57]ethylidene) malononitrile ( $\left[{ }^{18} \mathrm{~F}\right]$ FDDNP) $[57,58]$. With the Amsterdam Dementia Cohort, we set out to perform a head to head comparison, and found that $\left(\left[{ }^{11} \mathrm{C}\right]\right.$ PIB outperformed $\left[{ }^{18} \mathrm{~F}\right]$ FDDNP in group discrimination $[59,60]$. $\left[{ }^{11} \mathrm{C}\right] \mathrm{PIB}$ seemed more specific for amyloid pathology, based on stronger correlations with $A \beta$ in $\mathrm{CSF}$, while $\left[{ }^{18} \mathrm{~F}\right]$ FDDNP was related to CSF tau [61]. Of note, correlations with memory performance were in the same order of magnitude for both tracers, although specific correlations differed [62].

In a small study, we used (R)-[ $\left[{ }^{11} \mathrm{C}\right]$ verapamil and PET to estimate blood-brain barrier function, and found increased binding in $\mathrm{AD}$ patients compared to age-matched controls, providing the first in vivo evidence for compromised blood-brain barrier function in $\mathrm{AD}$ [63]. The modest effect size of the group differences did not suggest this marker to be of use in the context of diagnosis. Similarly, we used (R)- $\left[{ }^{11} \mathrm{C}\right] \mathrm{PK} 11195$ and PET to measure microglial activation, and although we observed increased inflammation in $\mathrm{AD}$, effect sizes did not suggest clinical usefulness with the current tracer [64].

\section{EEG and $M E G$}

According to the set-up of the Amsterdam Dementia Cohort, we perform EEG as part of our routine diagnostic workup. Based on a simple visual EEG rating of the presence of diffuse and/or focal abnormalities of more than one thousand memory clinic patients, we found that a normal EEG argues for SCD or psychiatric diagnosis; an EEG with only focal abnormalities supports MCI, an EEG with only diffuse abnormalities argues for $\mathrm{AD}$, and an EEG with both focal and diffuse abnormalities argues for DLB, vascular dementia $(\mathrm{VaD})$, or $\mathrm{AD}[65,66]$. Overlap between groups is considerable though. The observation of epileptiform discharges as determined by visual rating of a routine EEG is rare and nonspecific in our memory clinic cohort [67]. Comparing the power spectra, we observe in AD patients more slow wave activity (higher delta and theta) and less fast activity (lower alpha and beta power) than controls [68].

In addition to EEG, we have magnetoencephalogram (MEG) available for a subset of patients. MEG allows detailed spatial resolution and is especially suitable for functional connectivity analyses [69]. Using MEG, we have shown loss of communication between different functional brain regions, change in information flow, and slowing of hippocampal activity in $\mathrm{AD}$ [70-74]. We have recently implemented MEG in our diagnostic workup, and are currently evaluating the feasibility and usefulness of this approach.

\section{Diagnostic value}

In particular, the advent of methods to measure amyloid and tau in CSF and amyloid PET has had an important impact on the field. Studies comparing groups from the ADC as well as others showed reliable differences on a group level, but for these measures to be implemented in clinical practice, it is of the utmost importance to know how the markers behave in clinical practice, and how the clinician values their information [75]. The highly standardized organization of the diagnostic workup of the VUmc Alzheimer center has proven very useful to evaluate the diagnostic value of both CSF and PET [76-78]. For each of these studies, we took as outcome measures 1) change in diagnosis, 2) change in confidence in diagnosis, and 3) change in patient management. The studies differed in the diagnostic tool under study and the population under study.

To evaluate the diagnostic value of CSF biomarkers, we retrospectively compared profiles of biomarkers in almost 1,200 patients from the Amsterdam Dementia Cohort, and confirmed that CSF $\mathrm{A} \beta_{42}$, t-tau, and p-tau are useful in differential dementia diagnosis. In DLB, FTLD, VaD, and corticobasal degeneration, however, a substantial group exhibit a CSF AD biomarker profile [79]. Subsequently, we prospectively evaluated the use of CSF biomarkers during one year [76]. We offered lumbar puncture to all patients presenting at our memory clinic, and performed a lumbar puncture in $80 \%$ of patients. Disclosure of CSF results to the neurologist led to a change in diagnosis in $7 \%$, there was a significant increase in diagnostic confidence from $84 \%$ to $89 \%$ $(p<0.001)$, and consequences in patient management 
were noted in $13 \%$ of patients with CSF, compared to $15 \%$ because of the unavailability of CSF (e.g., PET).

We evaluated the use of molecular imaging using PET in a first study paired $\left[{ }^{18} \mathrm{~F}\right]$ FDG and $\left[{ }^{11} \mathrm{C}\right]$ PIB in 154 mixed memory clinic patients [77]. PET results led to a change in diagnosis in $23 \%$ of patients. This only occurred when prior diagnostic certainty was $<90 \%$. Diagnostic confidence increased from $71 \pm 17 \%$ before to $87 \pm 16 \%$ after PET $(p<0.001)$. As $\left[{ }^{18} \mathrm{~F}\right]$ amyloid tracers improve the applicability of amyloid PET in clinical practice, we performed a follow-up study to evaluate diagnostic value of $\left[{ }^{18} \mathrm{~F}\right]$ Flutemetamol in 211 patients with a differential diagnosis of early onset dementia [78]. After disclosure of PET results, $19 \%$ diagnoses changed. Overall, diagnostic confidence increased from $69 \pm 12 \%$ to $88 \pm 15 \%$ after disclosing PET results $(p<0.001)$. In $37 \%$, PET results led to a change in patient management; predominantly the initiation of $\mathrm{AD}$ medication in case of amyloid positivity.

Concordance between amyloid as measured using CSF and PET is good, with $84 \%$, providing convergent validity for the use of both types of biomarkers as measures of AD pathology [41]. Although at first sight, it seems as though the ratio of $A \beta$ and tau has better concordance with amyloid-PET than CSFamyloid alone, this can actually be explained by the fact that discordance is mostly seen in MCI and $\mathrm{AD}$ patients close to the cut-point of CSF A $\beta$. This can be solved by choosing a higher cut-point of CSF A $\beta$ and may actually demonstrate a sub-optimal cut-point of CSF A $\beta$.

We have not performed a similar study on diagnostic value of MRI measures, as MRI is an integral part of routine diagnostic workup and integrated in all available routine guidelines. As such, it is not feasible to establish diagnoses first without, and then with knowledge on MRI results, like we did for CSF and PET, both still in a research phase. Nonetheless, we have retrospectively evaluated diagnostic performance of visual rating scales in the largest set of memory clinic patients to date, and found that age and diagnosis both affect the scores on visual rating scales [11]. In addition, within the context of the Geneva Road Map endeavor, MTA rating and volumetric assessment of hippocampal atrophy were shown to be at the most developed stage compared to all other biomarkers. Remaining issues include cost-effectiveness and compliance in various settings (outside academia) and comparison of different protocols [80].
Contrary to the study on diagnostic value of CSF biomarkers, where we evaluated an unselected memory clinic cohort, for amyloid PET until now we have evaluated selected research populations. As a next step, we are currently performing a study where we offer amyloid PET to all patients presenting at our memory clinic [81]. This will allow to evaluate the diagnostic value in an unbiased way and help to validate and refine the appropriate use criteria, that have until now been based on experience opinion, rather than empirical evidence. In addition, we have now made a start to obtain the view of patients and caregivers with respect to diagnostic testing and the communication of these results [82-84]. In view of the dawning future with available disease modifying medication, the topic of shared decision making is highly timely in the context of diagnostic testing for AD.

These studies have been key to the development of the research criteria for AD by the International Working Group (IWG) led by Bruno Dubois, Feldman, and Scheltens [85-87].

\section{Functional decline}

Problems with everyday functioning, i.e., instrumental activities of daily living (IADL) is a key symptom and defining diagnostic criterion for any type of dementia. As in the Amsterdam Dementia Cohort, we see a fairly young population, we stumbled into the fact that virtually every IADL scale available, was decades old and hence not aligned with today's everyday activities (including computers, internet use, remote controls, mobile phones, etc.). In addition, a review of available IADL scales revealed that virtually none of the available scales had adequate test characteristics in terms of reliability and validity [88]. We set out to develop a novel instrument to measure IADL, the Amsterdam-IADLQuestionnaire (A-IADL-Q) in a computerized, adaptive way with input from patients and caregivers, professionals, and researchers $[89,90]$. In the years to follow, we have demonstrated the A-IADL-Q to have sufficient reliability and validity, good diagnostic value, and sensitive to capture changes over time [89, 91, 92]. We now have developed a shorter and thus more user-friendly version, that nonetheless maintained its favorable psychometric qualities [93]. The A-IADL-Q can be used in clinical practice and also in research settings-particularly as outcome measure in intervention studies attempting to have a beneficial effect on progression of the disease. 


\section{FROM DIAGNOSIS TO PROGNOSIS}

\section{Mild cognitive impairment}

The group of patients with MCI constitutes roughly $10 \%$ of the total ADC. Even though relatively small, it has been a very important group from the start. Both from a clinical and from a research perspective, patients with MCI are very relevant. In the course of three years follow-up, roughly half of them will show progression to dementia, most often due to $\mathrm{AD}$, while the other half remains clinically stable. During the past two decades, a large number of studies have been published to evaluate predictive value of diagnostic markers for progression to (AD) dementia in MCI patients.

MRI measures of atrophy, particularly the medial temporal lobe, but also more extended into the cortex, are associated with an increased risk of progression to dementia [16, 17, 94, 95]. Although baseline whole brain volume is predictive of incipient $A D$, we observed that rate of whole brain atrophy over time is strongly associated with an increased risk of progression to dementia [35].

When we analyzed visual rating scales in a sample of more than $150 \mathrm{MCI}$ patients with clinical followup, we found atrophy of the medial temporal lobe to be associated with an increased risk of AD dementia, while markers of small vessel disease (white matter hyperintensities (WMH), microbleeds) are associated with an increased risk of non-AD dementia (mainly $\mathrm{VaD})$ [19]. When we repeated these analyses in a larger sample, we found that MTA had modest predictive value of progression to dementia, while $\mathrm{WMH}$ did not predict progression to dementia [11].

Measures of brain activity using rs-fMRI, ASL, and EEG show that MCI patients have functional connectivity values in between $\mathrm{AD}$ dementia and controls, but predictive value of these measures seems limited [22-24, 96]. Combining modalities may improve their predictive value. Alternatively, these functional measures show changes later on in the disease cascade and have more value in monitoring disease progression in the dementia stage, when many of the conventional measures have reached bottom or ceiling levels.

CSF biomarkers have strong predictive value for predicting progression to $\mathrm{AD}$ dementia, with predictive value of CSF tau being highest in our sample [97, 98]. Injury markers CSF-tau and medial temporal lobe atrophy are associated with rate of progression to AD dementia [99, 100]. The different biomark- ers capture different aspects of the disease, and hence combining measures from different modalities further improves classification. In a recent study, we developed prognostic risk models that attribute probabilities for dementia risk after one year and after three years based on specific CSF and/or MRI measures for a patient with a given age, gender and Mini-Mental State Examination (MMSE) [101]. This paper provides a framework that allows to think about a future of precision medicine, taking biomarkers to the individual level.

Using $\left[{ }^{11} \mathrm{C}\right] \mathrm{PIB}$, we found amyloid load and hypometabolism to be related to cognitive decline over time. Moreover, in MCI patients, we observed an increase in amyloid load over time [102, 103].

\section{Subjective cognitive decline}

With the shifting interest to ever earlier stages of the disease, individuals with SCD became a population of interest [104]. Roughly one quarter of the patients visiting our memory clinic worry about their memory. Yet, after thorough investigation, they are diagnosed as cognitively normal, i.e., SCD. In one of the earliest studies on this topic, we demonstrated that SCD patients are more often APOE $\varepsilon 4$ positive than individuals from the general population [105]. Most patients presenting with SCD at a memory clinic do not harbor AD or any other neurodegenerative disease. Yet, a minority of these individuals may actually subjectively experience subtle decline, which cannot yet be captured on routine clinical testing. The question is how to identify those individuals with SCD that are at risk of clinical progression.

In a study following individuals with SCD over time, we found that abnormal CSF biomarkers, particularly concentrations of $\mathrm{A} \beta$, are associated with subsequent decline to MCI or dementia [106]. In a subsequent study, we classified patients according to the proposed stages of preclinical $\mathrm{AD}$ and found that SCD patients fulfilling biomarker criteria for stage 1 and 2 preclinical AD showed decline in memory and executive functions in the years to follow. By contrast, in SCD patients with normal biomarkers or suspected non-Alzheimer's pathophysiology (elevated tau, but normal $A \beta$ levels), a slight improvement in cognition over time was visible, illustrating the negative predictive value of these markers. These results prompted us to use SCD as a model to study preclinical AD. This population could be of the utmost help to answer the question which markers predict clinical progression, but also study the cascade of events from cogni- 
tively normal to dementia. In follow-up studies, we found that CSF concentrations of ApoE and ApoA1 were associated with incipient clinical progression, particularly in APOE $\varepsilon 4$ carriers, suggesting that these proteins have a role in the early stages of $\mathrm{AD}$ [107, 108].

On MRI, we found that both atrophy of the medial temporal lobe as well as severe $\mathrm{WMH}$ are associated with clinical progression [109, 110]. Finally, we observed on EEG, that with amyloid positive individuals with SCD, slowing of oscillatory brain activity is related to rate of clinical progression [111].

\section{CLINICAL MANIFESTATION}

There is large heterogeneity in clinical manifestation of dementia. Some of this variation is attributable to different types of dementia presenting with a different clinical syndrome, but even within AD there is large variation.

\section{Subgroups of $A D$}

The first and most salient symptom of $A D$ is episodic memory impairment. Nonetheless, there are also patients who have a non-memory presentation. Extreme forms of such non-memory presentations include PCA, logopenic variant $\mathrm{AD}$, or the behavioral/dysexecutive variant [112-114]. These extreme phenotypes are relatively rare, and in our Amsterdam Dementia Cohort we observed that also within the regular spectrum $\mathrm{AD}$ there is phenotypic variation. Therefore, we systematically analyzed phenotypic heterogeneity in AD in terms of brain structure, function, and amyloid deposition, taking age-at-onset as a starting point. In addition, we evaluated the effect of APOE genotype on phenotype.

In an early study we went back to patient files to evaluate presenting complaints, and found that older patients almost invariably present with memory problems, but by contrast, almost one out of three of the younger $\mathrm{AD}$ patients presented with non-memory problems, such as problems in visuo-spatial functions, language, or executive functions [115]. In a follow-up study, we compared older and younger AD patients and found that the neuropsychological profiles almost mirrored each other, with memory being most prominently impaired in older patients, but relatively spared in the younger AD patients (Fig. 3) [116]. On MRI, atrophy of the medial temporal lobe is the most salient characteristic. When we compared older and younger $\mathrm{AD}$ patients with age-matched

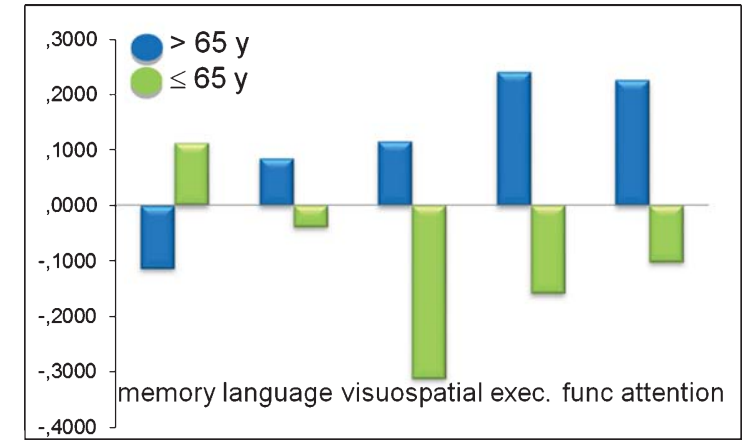

Fig. 3. Mean neuropsychological Z-scores by age at onset of Alzheimer's disease (AD). Note that this is a comparison of different groups of patients, hence average cognitive performance is impaired, and the bars show relative sparing or more prominent impairment per subgroup. The $\mathrm{x}$-axis shows the five cognitive domains: memory, language, visuo-spatial functioning, executive functioning and attention. The y-axis shows the mean z-scores for patients with early onset $\mathrm{AD}(n=81,60 \pm 4$ years, $54 \% \mathrm{~F}$, MMSE: $20 \pm 5$; green bars) and late onset $\mathrm{AD}(n=91,72 \pm 5$ years, $52 \%$ F, MMSE: $21 \pm 5$; blue bars). Univariate analyses of variance with age at onset as between-subject factor and sex and education as covariates showed that early onset patients performed worse than late onset patients on visuo-spatial functioning $(p<0.01)$, executive functioning $(p<0.001)$ and attention $(p<0.01)$. Late onset patients performed worse on memory, although not significantly $(p=0.11)$. This figure is based on one published in Smits et al. [116], reprinted with permission from IOS Press.

controls using VBM, we found that atrophy in late onset patients was most prominent in the (medial) temporal lobe $[14,15]$. In patients with early onset, however, we found far more widespread atrophy, in the hippocampus, temporal lobes, precuneus, cingulate gyrus, and frontal cortex. In a direct comparison, we found that younger patients have more severe precuneus atrophy, despite their younger age. When we analyzed associations with cognitive impairment, we found that within a large group of AD patients, atrophy of the medial temporal lobe was associated with worse performance on memory, language, and attention tasks, while atrophy of the posterior cortex was associated with worse performance on visuospatial and executive functioning [12]. Subsequently, we analyzed differences in brain activity as assessed using EEG and found that early onset AD patients and APOE $\varepsilon 4$ negative patients show more severe slowing of the EEG, especially in the posterior regions of the brain $[66,68,117]$. When we categorized a large group of AD patients based on the presence of focal and/or diffuse EEG abnormalities and compared the cognitive profiles, we observed that patients with a normal EEG had a typical memory profile of cognitive impairment [118]. Patients who 
displayed both focal and diffuse abnormalities displayed a non-memory cognitive profile. These results show that variation in brain activity links to cognitive profile.

When we compared CSF A $\beta$ between older and younger patients, we found that early and late onset AD patients had similarly low levels of A $\beta$. Discriminatory value seems better in younger patients, but this is attributable to younger controls having higher concentrations of $A \beta$ than older controls. In view of the limited associations between amyloid burden and severity of disease, limited associations with phenotypic variation could be expected. Indeed, when we used $\left[{ }^{11} \mathrm{C}\right]$ PIB PET to estimate global amyloidburden in younger and older AD patients, we found no differences between groups [119]. However, when we looked at the regional distribution of amyloid we found a subtle difference, with younger $\mathrm{AD}$ patients having a higher amyloid load in the parietal cortex than older patients. We found a similar effect when we compared AD subgroups based on APOE $\varepsilon 4$ genotypes, with $\varepsilon 4$ noncarriers having more frontal amyloid binding [120].

Together these studies point toward meaningful heterogeneity in $\mathrm{AD}$, which is not restricted to a few atypical cases, but rather is subtly evident throughout the entire spectrum of patients. We observe heterogeneity in terms of cognition, brain structure and function, and even amyloid deposition, and can link this to age-at-onset and APOE genotype [121, 122]. All these studies took a top-down approach to define subgroups. It is quite unlikely, however, that age-at-onset determines phenotype. Rather, there is probably some underlying characteristic or set of characteristics that influences both age-at-onset and other phenotypic characteristics. In our next studies, we took a bottom-up approach and identified different cognitive subtypes, based on cognitive data $[123,124]$. Furthermore, we found that group membership was related to demographic and biologic variables, with atypical $A D$ patients being younger, more often APOE $\varepsilon 4$ negative, showing a relatively spared hippocampus, but more posterior atrophy.

\section{Rate of progression}

For patients, a diagnosis of $\mathrm{AD}$ is not the end of a process, but rather the beginning of the rest of their disease. After they have learned what their diagnosis is and that curative therapy is not available, the third question patients often ask in the consulting room is "doctor, what can I expect". And this question is still very difficult to answer. By definition, patients with dementia show decline over time. But the rate of decline varies widely between individuals.

We found that younger patients, particularly when APOE $\varepsilon 4$ negative, show faster cognitive decline, particularly on the non-memory cognitive domains [125, 126]. In line with these findings, younger patients and APOE $\varepsilon 4$ negative patients were also prone to a higher rate of whole brain atrophy [127]. Taking CSF biomarkers as a starting point, we found that none of the CSF biomarkers was associated with baseline MMSE, but patients with strongly elevated tau without proportionally elevated ptau were at risk of faster rate of cognitive decline [128]. Finally, we found that AD patients with lower cerebral blood flow, particularly in posterior regions, are prone to faster cognitive decline [129].

When we used mortality as an outcome measure, we found that the risk of mortality is strongly increased in younger patients compared to agematched controls, while the risk of mortality is only modestly increased in older patients [130]. Looking at MRI, both WMH and microbleeds were associated with increased risk of mortality, while after age adjustment, the effect of atrophy lost significance [131]. When we took an opposite approach, taking short survival ( $<2$ years after diagnosis) as a starting point, we found that short survival is relatively common (approximately 13\% of our cohort) and occurs in all different types of dementia, with overrepresentation of non-AD dementia's like Creutzfeldt-Jakob disease, VaD, and FTD [132].

\section{Frontotemporal dementia}

Accurate biomarkers for FTD still are not available. In younger patients, FTD is the second most common cause of dementia and hence the differential diagnosis between FTD and AD is an important challenge. Ruling out $\mathrm{AD}$ has become possible by using AD sensitive and specific CSF and PET biomarkers, but ruling in FTD, especially in the distinction with psychiatric disorders remains a challenge. Within the broader spectrum of the Amsterdam Dementia Cohort, the Late Onset Frontal Lobe study aims to evaluate the spectrum of etiologies underlying late onset frontal syndrome and to discern bvFTD from the broadest clinically relevant differential diagnosis including psychiatric disorders [133]. We found that bvFTD patients show more subcortical atrophy and diminished integrity of white matter tracts than $\mathrm{AD}$ patients, illustrating that FTD may be viewed even 
more as a fronto-subcortical network disease [26, 27]. This is further corroborated by our observation of disease specific gray matter network changes, when comparing bvFTD with AD patients, which were moreover associated with cognitive deficits [134]. These studies show that combining modalities, and perhaps also using repeated MRI can be of help to differentiate bvFTD from AD [28, 31]. Using MRI and FDG PET, we showed a good diagnostic accuracy for the combination of MRI and $\left[{ }^{18}\right.$ F]FDG-PET for bvFTD in patients with late onset behavioral changes [135]. MRI had a sensitivity of $70 \%$ with a specificity of $93 \%$. Additional $\left[{ }^{18}\right.$ F]FDG-PET had a sensitivity of $90 \%$ with a specificity of $68 \%$. The sensitivity of combined neuroimaging was $96 \%$ with a specificity of $73 \%$. In an attempt to find more specific biomarkers for the distinction between FTD and psychiatric disorders we found that the combination of Neurofilament light, ptau/tau ratio, and YKL 40 had a sensitivity of $91 \%$ at a specificity of 83\% with an AUC of 0.94 for bvFTD [136]. Further research concentrates on the longitudinal behavioral changes and specific psychiatric changes in FTD versus psychiatric disorders.

\section{Dementia with Lewy bodies}

DLB is the second most degenerative cause of dementia. We have shown more diffuse slow wave activity and frontal intermittent delta activity rated visually in DLB patients compared to AD patients [137]. EEG changes have now been incorporated in the DLB criteria [138, 139]. We have shown that roughly half of patients with DLB is positive for AD biomarkers [79]. Comparing AD biomarker positive to $\mathrm{AD}$ biomarker negative DLB patients, we found that this additional pathology affects clinical presentation, in terms of worse memory performance and more frequent hallucinations, higher rate of nursing home admittance and shorter survival [140]. DLB-specific CSF biomarkers have until now not been successful. In an early study, we measured alpha-synuclein and were not able to discriminate between groups, although we found some associations between alpha-synuclein concentration and cognitive performance in DLB [141]. We are currently evaluating novel assays for alpha-synuclein which may provide more sensitive and specific measures for alpha-synucleopathy. To date, the most specific measure for DLB is the DAT scan. Nonetheless, initial DAT scans may also be negative. In a small series of initially DAT-negative DLB patients, we showed that this does not preclude DLB, as DAT scan may become positive a year later [142].

\section{Disease course in types of dementia}

Based on the Amsterdam Dementia Cohort, we have been able to compare different types of dementia with respect to disease course. In terms of mortality, and adjusted for age, we found that AD seemed to have the most benign course, with a fourfold increased mortality risk compared to controls [130]. DLB and VaD (frequently seen at older age) and FTLD and 'other dementias' (often found at younger age) had a six- to eightfold increased mortality risk. When we took patients with a rapid disease course (mortality within two years) as starting point, we found that short survival is relatively common (approximately 13\% in our cohort) and occurs in all different types of dementia, with overrepresentation of non-AD dementias like Creutzfeldt-Jakob disease, $\mathrm{VaD}$, and FTD [132]. Comparing trajectories of cognitive decline across different types of dementia, we found that during follow-up, DLB patients showed decline in every cognitive domain except language and global cognition [143]. Patients with bvFTD showed rapid decline in memory, language, attention, and executive functioning whereas visuospatial functioning remained fairly stable. VaD showed decline in attention and executive functioning.

\section{VASCULAR FACTORS}

AD pathology and vascular pathology, particularly small vessel disease, often occur together. It is not yet clear whether the two types of pathology occur simultaneously but independently, whether one type of pathology triggers the other, or whether they are in fact two sides of the same coin. MRI measures of small vessel disease include $\mathrm{WMH}$, lacunes, and microbleeds.

\section{White matter hyperintensities}

MRI studies into vascular factors of AD started with WMH. The observation of WMH on MRI of AD patients was one of the first descriptions of heterogeneity in $\mathrm{AD}$ in the nineties of the last century [144]. In this period, Scheltens developed a scale to rate periventricular and deep WMH [145]. A number of studies with respect to WMH have been performed in the Amsterdam Dementia Cohort. In a group of AD 
patients, we found associations between WMH volume and mental speed [146]. And in SCD and MCI, we found that severe WMH are associated with clinical progression, albeit not with a large effect size $[19,109]$.

\section{Microbleeds}

For a long time, microbleeds were regarded as innocent observations. At the beginning of the new millennium, we counted microbleeds in the Amsterdam Dementia Cohort, and found that microbleeds are more common in patients with $\mathrm{AD}$ or MCI than in controls [147]. Microbleeds are thought to be expressions of underlying cerebral amyloid angiopathy, particularly when they have a lobar location (Fig. 4). By contrast, microbleeds with a deep location are supposedly related to vascular hypertension. Microbleeds often occur in the presence of other expressions of small vessel disease, but may also occur in isolation. In line with this observation, we found that risk factors for WMH and microbleeds differ, with age, hypertension, smoking, and lacunes being related to the presence of $\mathrm{WMH}$, while male gender, higher blood pressure, lower CSF A $\beta$, and APOE $\varepsilon 4$ homozygosity were related to microbleeds, suggesting that microbleeds are related to the AD disease pathophysiology [148]. In a series of papers, we established the clinical significance

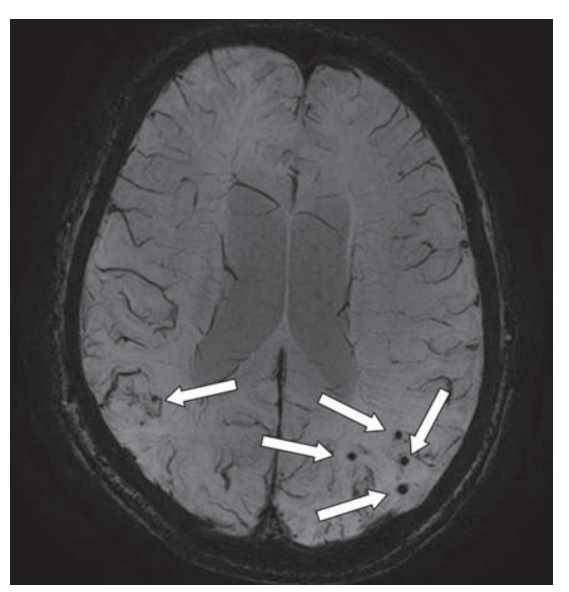

Fig. 4. An axial MRI image of a susceptibility weighted image (SWI) that provides information on the presence of microbleeds (arrows; occipital part of the cortex). This is an image of a 68-yearold male with a diagnosis of Alzheimer's disease. On presentation, he had an MMSE of 23. On MRI, there was evidence of moderate atrophy of the medial temporal lobe, mild global cortical atrophy, beginning confluent white matter hyperintensities and multiple microbleeds (mostly with a lobar location). of microbleeds and found that patients with many microbleeds have worse cognitive performance at baseline, more WMH, and more abnormal CSF concentrations of $A \beta$ despite similar disease duration and degree of atrophy [149]. In follow-up studies, we confirmed that $\mathrm{AD}$ patients with microbleeds have lower levels of CSF A $\beta[150,151]$. Furthermore, microbleeds are associated with an increased risk of stroke and mortality, but not of more rapid cognitive decline $[131,152,153]$. Finally, we observed over a followup period of two years that $12 \%$ of patients developed new microbleeds, showing that novel microbleeds develop in a naturalistic cohort [154]. Determinants of new microbleeds were APOE $\varepsilon 4$ genotype, presence and progression of MRI measures of small vessel disease, and vascular risk factors.

\section{Cerebral blood flow}

In the quest for the combination of $\mathrm{AD}$ and vascular pathology, cerebral blood flow is an interesting measure. ASL allows quantitative and regional measurement of cerebral perfusion. Using ASL, we observed reduced cerebral blood flow in AD patients and other types of dementia compared with controls $[24,25,96]$. Furthermore, cerebral perfusion is associated with cognitive impairment and rate of cognitive decline over time [129, 155]. It is unclear whether cerebral perfusion is reduced as a consequence of cerebrovascular pathology (i.e., indication of vessel disease), or whether atrophy of the brain results in less demand for oxygen (i.e., indication of neurodegeneration). Similar and independent associations of whole brain volume and WMH with ASL measured cerebral blood flow suggest that cerebral perfusion may reflect the combined disease burden of neurodegeneration and small vessel disease [156]. This could make ASL particularly suitable as a secondary outcome measure for clinical trials. We are currently performing a trial in patients with vascular cognitive impairment with a physical activity intervention, where we use ASL measured cerebral blood flow as the primary outcome measure [157].

\section{OUTLOOK: WHAT DID WE BRING THE PATIENT}

Looking back over the past 17 years, the Amsterdam approach of closely linking care and research has proven quite fruitful. What are the lessons learned? The most important starting-point is the multidisciplinary nature of both care and research of dementia. 
It is essential to involve all stakeholders from the beginning and show them that by creating this workup in the sense of standardizing assessments and providing data for research, there is added value for all. As such, our program has been beneficial not only for the Alzheimer center itself, which is based at the department of Neurology, but also for other departments throughout the hospital and our research institute Amsterdam Neuroscience. As a result, all partners are committed to keep the program running smoothly. The Dutch health care system provides coverage for all the investigations carried out, as indicated by the national guidelines. Collection of CSF has been done within the research setting and paid out of research budgets until 2015, when, based on available evidence, it was put into routine practice. Our recommendation is to engage in discussion with all partners involved and show them that combining research and care will benefit all and, in the end, will yield more than it costs.

If we try to summarize what our research within the ADC cohort, in which our patients helped us to answer questions, yielded to our patients, we like to illustrate this by focusing on the three most important questions patients ask when they come to the clinic.

\section{What is my diagnosis?}

Since the start of the ADC we have come a long way in answering this question. We helped develop MRI, CSF, and PET biomarkers to the point that most of them have reached the clinic and can be used diagnostically with high positive and negative likelihood ratios, mainly in the distinction between $\mathrm{AD}$ and normal aging and other dementias, even at the MCI stage and be prognostic in the SCD stage. The added effect in terms of diagnostic certainty, ability to increase clinician's confidence, and ability to change management has become evident. Current IWG and NIA/AA criteria highlight the status of the markers in research and clinical practice. In the current situation, amyloid PET is available for care, but only a small number of patients each year receive a clinical amyloid PET scan. In the large majority of cases, amyloid PET is still offered as part of a research program. Tau imaging is only performed in the context of research. By contrast, DAT-SPECT and FDG-PET are available for care. Despite the advances in diagnostic tests for AD, we have done less well in finding and testing biomarkers for the other degenerative dementias, but specific MRI patterns, FDG-PET changes, and absence of amyloid may help the clinician tremendously.
Challenges for the near future are: specific biomarkers in CSF for other types of dementia, clinical validation of tau-PET and development of novel tracers (both specific for other types of dementia and capturing other aspects of AD), and finding bloodbased biomarkers, which could serve as a screening tool.

\section{What is my prognosis?}

Contrary to what we hoped and aimed for, biomarker prediction of the course of the disease in $\mathrm{AD}$ patients is still very difficult. Even though on a group level we have found some indicators of faster or slower progression, precision is still too low to allow direct translation to individual patients. Yet, the worldwide availability of ever-growing data sets such as ours may make it possible to think of a future of precision medicine, where we are actually able to use biomarker information to provide individual patients with tailored prognostic information. As part of the ongoing ABIDE study, we have developed a biomarker prediction tool which allows a clinician to interpret biomarker levels of an individual patient to individualized risk probabilities [101]. If validated in other cohorts, such a tool may help clinicians and patients to determine the course of the illness and improve management of the disease.

\section{Is there a therapy?}

Beyond what we currently can do with cholinesterase inhibitors and memantine, there is virtually nothing we can offer our patients other than organizing care, lifestyle advice, and the possibility to enter clinical trial programs. Therefore, at the VUmc Alzheimer center, we attempt to provide patients and their families with high quality information on their-often relatively rare-disease. We offer care counseling by a specialized nurse and genetic counseling for individuals with a suspicious family history. In addition, we organize support groups for specific patient groups, including PCA, FTD, and primary progressive aphasia. We organize monthly 'lunch and learn' meetings to inform patients, their families, and care professionals on current issues in care and research. Finally, our website has been designed in such a way that patients can find a lot of information on their disease, including a forum and research blog functionality.

However, in view of the huge progress in the field as described above, the ultimate outlook for developing 
drugs to target the underlying pathology, amyloid and tau, seems at the horizon. A biomarker-based diagnosis is key to the development of proper personalized treatment and is essential to advance the field [5]. We expect that by 2025 , both diagnosis and treatment of dementia will have changed profoundly, in such a way that a molecular diagnosis (which proteinopathies contribute to which extent to the clinical picture in a given patient) will form the basis for personalized therapy, targeted at specific proteinopathies. For that scenario to become real, a huge amount of research effort still needs to be done, and we are confident and happy to be able to contribute to these exciting times with the ongoing Amsterdam Dementia Cohort!

\section{ACKNOWLEDGMENTS}

Research of the VUmc Alzheimer center is part of the neurodegeneration research program of Amsterdam Neuroscience (http://www.amsterdamresearch. org). The VUmc Alzheimer Center is supported by Stichting Alzheimer Nederland and Stichting VUmc fonds. The clinical database structure was developed with funding from Stichting Dioraphte. Research programs have been funded by ZonMW, NWO, EUFP7, EU-Joint Programming for Neurodegenerative Diseases, EU-IMI, Alzheimer Nederland, CardioVascular Onderzoek Nederland, stichting Dioraphte, Gieskes-Strijbis fonds, Boehringer Ingelheim, Piramal Neuroimaging, Roche BV, Janssen Stellar, Probiodrug, Combinostics, Biogen MA Inc.

The work described in this cohort is fruit of the work of many colleagues and collaborators throughout the years. Staff: Yolande Pijnenburg, Evelien Lemstra, Femke Bouwman, Niels Prins, Freek Gillissen, Pieter Jelle Visser, Sietske Sikkes, Betty Tijms. Current employees: Anne Catrien Baakman, Rosha Babapour Mofrad, Maryam Badissi, Frederik Barkhof, Nina Beker, Marleen van de Beek, Bart van Berckel, Daniela Bertens, Casper de Boer, Karlijn van den Bosch, Baayla Boon, Anouk den Braber, Casper Briels, Marieke van Buchem, Karin Brink-Goede, Lyduine Collij, Anita Dekker, Els Dekkers, Nicolle Dellaert, Ellen Dicks, Annemieke Dols, Floor Duits, Astrid Doorduijn, Jay Fieldhouse, Leonie Franken, Agnetha Fruijtier, Ronald Gabel, Alida Gouw, Colin Groot, Jurre den Haan, Marieke Hamming, Henne Holstege, Astrid Hooghiemstra, Debbie Horsten, Marc Hulsman, Silvia Ingala, Iris Jansen, Roos Jutten, Mara ten Kate, Maartje Kester, Elles Konijnenberg, Elisa de Koning, Isadora Lopes Alves, Sven van der Lee, Philippe Lee Meeuw Kjoe, Francien de Leeuw, Céline Leeuwestein, Annebet Leeuwis, Mardou van Leeuwenstijn, Nienke Legdeur, Jolien Leijenaar, Rosanne Leguijt, Mascha Linszen, Anita van Loenhoud, Ingrid van Maurik, Lea ter Meulen, Ghiselinde Meijs, Sandra Mulder, Lynn van Olst, Rik Ossenkoppele, Wiesje Pelkmans, Lianne Reus, Sterre Rechtuijt, Margo van Roon, Hanneke Rhodius, Carolijn Scheffer, Charlotte Schreuder, Salka Staekenborg, Kees Stam, Anna van der Steen, Inger van Steenoven, Charlotte Teunissen, Nicolo Tesi, Tessa Timmers, Lies Thijssen, Jori Tomassen, Astrid van Vark, Sander Verfaillie, Inge Verberk, Lisa Vermunt, Merike Verrijp, Jort Vijverberg, Denise Visser, Annelies van der Vlies, Sylvia Voogt, Silvia de Vries, Philine van der Weerd, Linda Wesselman, Arno de Wilde, Eline Willemse, Jurriaan Witteman, Emma Wolters, Jessica van der Zande, Marissa Zwan. Former $\mathrm{PhD}$ students (not working at AC anymore): Rutger Goekoop, Niki Schoonenboom, Esther Korf, Barbera van Harten, Bethany Jones, Laura van de Pol, Antonio Bastos Leite, Ilse van Straaten, Raymond Vogels, Jeske Damoiseaux, Giorgos Karas, Henriette van der Roest, Cees Mulder, Wouter Henneman, Nelleke Tolboom, Ellemarije Altena, Niek Verwey, Jasper Sluimer, Alie Schuitemaker, Karlijn Joling, Willem de Haan, Daniëlle Van Assema, Jeroen Goos, Hadassa Jochemsen, Ineke Van Rossum, Els Møst, Maja Binnenwijzend, Lieza Exalto, Hanneke de Waal, Wesley Jongbloed, Esther Koedam, Argonde van Harten, Lieke Sandberg-Smits, Sofie Adriaanse, Christiane Möller, Marta Del Campo Milan, Marije Benedictus, Eva Louwersheimer, Welmoed Krudop, Andrea Rosenberger.

Authors' disclosures available online (https:// www.j-alz.com/manuscript-disclosures/17-0850r2).

\section{REFERENCES}

[1] Scheltens P, Fox N, Barkhof F, De Carli C (2002) Structural magnetic resonance imaging in the practical assessment of dementia: Beyond exclusion. Lancet Neurol 1, 13-21.

[2] McKhann G, Drachman D, Folstein M, Katzman R, Price D, Stadlan EM (1984) Clinical diagnosis of Alzheimer's disease: Report of the NINCDS-ADRDA Work Group under the auspices of Department of Health and Human Services Task Force on Alzheimer's Disease. Neurology 34, 939-944.

[3] Petersen RC, Smith GE, Waring SC, Ivnik RJ, Tangalos EG, Kokmen E (1999) Mild cognitive impairment: Clinical characterization and outcome. Arch Neurol 56, 303-308.

[4] van der Flier WM, Pijnenburg YA, Prins N, Lemstra AW, Bouwman FH, Teunissen CE, van Berckel BN, Stam CJ, 
Barkhof F, Visser PJ, van EE, Scheltens P (2014) Optimizing patient care and research: The Amsterdam Dementia Cohort. J Alzheimers Dis 41, 313-327.

[5] Scheltens P, Blennow K, Breteler MM, De SB, Frisoni GB, Salloway S, van der Flier WM (2016) Alzheimer's disease. Lancet 388, 505-517.

[6] Scheltens P, Leys D, Barkhof F, Huglo D, Weinstein HC, Vermersch P, Kuiper M, Steinling M, Wolters EC, Valk J (1992) Atrophy of medial temporal lobes on MRI in "probable" Alzheimer's disease and normal ageing: Diagnostic value and neuropsychological correlates. J Neurol Neurosurg Psychiatry 55, 967-972.

[7] Scheltens P, Launer LJ, Barkhof F, Weinstein HC, van Gool WA (1995) Visual assessment of medial temporal lobe atrophy on magnetic resonance imaging: Interobserver reliability. J Neurol 242, 557-560.

[8] Koedam EL, Lehmann M, van der Flier WM, Scheltens P, Pijnenburg YA, Fox N, Barkhof F, Wattjes MP (2011) Visual assessment of posterior atrophy development of a MRI rating scale. Eur Radiol 21, 2618-2625.

[9] Moller C, van der Flier WM, Versteeg A, Benedictus MR, Wattjes MP, Koedam EL, Scheltens P, Barkhof F, Vrenken H (2014) Quantitative regional validation of the visual rating scale for posterior cortical atrophy. Eur Radiol 24, 397-404.

[10] van de Pol LA, Hensel A, Barkhof F, Gertz HJ, Scheltens P, van der Flier WM (2006) Hippocampal atrophy in Alzheimer disease: Age matters. Neurology 66, 236-238.

[11] Rhodius-Meester HFM, Benedictus MR, Wattjes MP, Barkhof F, Scheltens P, Muller M, van der Flier WM (2017) MRI visual ratings of brain atrophy and white matter hyperintensities across the spectrum of cognitive decline are differently affected by age and diagnosis. Front Aging Neurosci 9, 117.

[12] Smits LL, Tijms BM, Benedictus MR, Koedam EL, Koene T, Reuling IE, Barkhof F, Scheltens P, Pijnenburg YA, Wattjes MP, van der Flier WM (2014) Regional atrophy is associated with impairment in distinct cognitive domains in Alzheimer's disease. Alzheimers Dement 10, S299-S305.

[13] Harper L, Fumagalli GG, Barkhof F, Scheltens P, O'Brien JT, Bouwman F, Burton EJ, Rohrer JD, Fox NC, Ridgway GR, Schott JM (2016) MRI visual rating scales in the diagnosis of dementia: Evaluation in 184 post-mortem confirmed cases. Brain 139, 1211-1225.

[14] Karas G, Scheltens P, Rombouts S, Van Schijndel R, Klein M, Jones B, van der FW, Vrenken H, Barkhof F (2007) Precuneus atrophy in early-onset Alzheimer's disease: A morphometric structural MRI study. Neuroradiology 49, 967-976.

[15] Moller C, Vrenken H, Jiskoot L, Versteeg A, Barkhof F, Scheltens P, van der Flier WM (2013) Different patterns of gray matter atrophy in early- and late-onset Alzheimer's disease. Neurobiol Aging 34, 2014-2022.

[16] Karas G, Sluimer J, Goekoop R, van der FW, Rombouts SA, Vrenken H, Scheltens P, Fox N, Barkhof F (2008) Amnestic mild cognitive impairment: Structural MR imaging findings predictive of conversion to Alzheimer disease. AJNR Am J Neuroradiol 29, 944-949.

[17] Sluimer JD, van der Flier WM, Karas GB, Van Schijndel R, Barnes J, Boyes RG, Cover KS, Olabarriaga SD, Fox NC, Scheltens P, Vrenken H, Barkhof F (2009) Accelerating regional atrophy rates in the progression from normal aging to Alzheimer's disease. Eur Radiol 19, 2826-2833.
[18] Henneman WJ, Sluimer JD, Barnes J, van der Flier WM, Sluimer IC, Fox NC, Scheltens P, Vrenken H, Barkhof F (2009) Hippocampal atrophy rates in Alzheimer disease: Added value over whole brain volume measures. Neurology 72, 999-1007.

[19] Staekenborg SS, Koedam EL, Henneman WJ, Stokman P, Barkhof F, Scheltens P, van der Flier WM (2009) Progression of mild cognitive impairment to dementia: Contribution of cerebrovascular disease compared with medial temporal lobe atrophy. Stroke 40, 1269-1274.

[20] Binnewijzend MA, Adriaanse SM, van der Flier WM, Teunissen CE, de Munck JC, Stam CJ, Scheltens P, van Berckel BN, Barkhof F, Wink AM (2014) Brain network alterations in Alzheimer's disease measured by eigenvector centrality in fMRI are related to cognition and CSF biomarkers. Hum Brain Mapp 35, 2383-2393.

[21] Damoiseaux JS, Rombouts SA, Barkhof F, Scheltens P, Stam CJ, Smith SM, Beckmann CF (2006) Consistent resting-state networks across healthy subjects. Proc Natl Acad Sci U S A 103, 13848-13853.

[22] Binnewijzend MA, Benedictus MR, Kuijer JP, van der Flier WM, Teunissen CE, Prins ND, Wattjes MP, van Berckel BN, Scheltens P, Barkhof F (2016) Cerebral perfusion in the predementia stages of Alzheimer's disease. Eur Radiol 26, 506-514.

[23] Binnewijzend MA, Schoonheim MM, Sanz-Arigita E, Wink AM, van der Flier WM, Tolboom N, Adriaanse SM, Damoiseaux JS, Scheltens P, van Berckel BN, Barkhof F (2012) Resting-state fMRI changes in Alzheimer's disease and mild cognitive impairment. Neurobiol Aging 33, 2018-2028.

[24] Collij LE, Heeman F, Kuijer JP, Ossenkoppele R, Benedictus MR, Moller C, Verfaillie SC, Sanz-Arigita EJ, van Berckel BN, van der Flier WM, Scheltens P, Barkhof F, Wink AM (2016) Application of machine learning to arterial spin labeling in mild cognitive impairment and Alzheimer disease. Radiology 281, 865-875.

[25] Binnewijzend MA, Kuijer JP, van der Flier WM, Benedictus MR, Moller CM, Pijnenburg YA, Lemstra AW, Prins ND, Wattjes MP, van Berckel BN, Scheltens P, Barkhof F (2014) Distinct perfusion patterns in Alzheimer's disease, frontotemporal dementia and dementia with Lewy bodies. Eur Radiol 24, 2326-2333.

[26] Moller C, Dieleman N, van der Flier WM, Versteeg A, Pijnenburg Y, Scheltens P, Barkhof F, Vrenken H (2015) More atrophy of deep gray matter structures in frontotemporal dementia compared to Alzheimer's disease. J Alzheimers Dis 44, 635-647.

[27] Moller C, Hafkemeijer A, Pijnenburg YA, Rombouts SA, van der Grond J, Dopper E, van SJ, Versteeg A, Pouwels PJ, Barkhof F, Scheltens P, Vrenken H, van der Flier WM (2015) Joint assessment of white matter integrity, cortical and subcortical atrophy to distinguish AD from behavioral variant FTD: A two-center study. Neuroimage Clin 9, 418429.

[28] Moller C, Hafkemeijer A, Pijnenburg YA, Rombouts SA, van der Grond J, Dopper E, van Swieten J, Versteeg A, Steenwijk MD, Barkhof F, Scheltens P, Vrenken H, van der Flier WM (2016) Different patterns of cortical gray matter loss over time in behavioral variant frontotemporal dementia and Alzheimer's disease. Neurobiol Aging 38, 21-31.

[29] Koikkalainen J, Rhodius-Meester H, Tolonen A, Barkhof F, Tijms B, Lemstra AW, Tong T, Guerrero R, Schuh A, 
Ledig C, Rueckert D, Soininen H, Remes AM, Waldemar G, Hasselbalch S, Mecocci P, van der Flier W, Lotjonen J (2016) Differential diagnosis of neurodegenerative diseases using structural MRI data. Neuroimage Clin 11, 435-449.

[30] Vijverberg EG, Tijms BM, Dopp J, Hong YJ, Teunissen CE, Barkhof F, Scheltens P, Pijnenburg YA (2017) Gray matter network differences between behavioral variant frontotemporal dementia and Alzheimer's disease. Neurobiol Aging 50, 77-86.

[31] Moller C, Pijnenburg YA, van der Flier WM, Versteeg A, Tijms B, de Munck JC, Hafkemeijer A, Rombouts SA, van der Grond J, van Swieten J, Dopper E, Scheltens P, Barkhof F, Vrenken H, Wink AM (2016) Alzheimer disease and behavioral variant frontotemporal dementia: Automatic classification based on cortical atrophy for single-subject diagnosis. Radiology 279, 838-848.

[32] Tijms BM, Moller C, Vrenken H, Wink AM, de HW, van der Flier WM, Stam CJ, Scheltens P, Barkhof F (2013) Single-subject grey matter graphs in Alzheimer's disease. PLoS One 8, e58921.

[33] Tijms B, Kate MT, Gouw A, Verfaillie SC, Teunissen C, Scheltens P, Barkhof F, Van der Flier WM (2018) Grey matter connectivity is associated with clinical progression in non-demented patients. Neurobiol Aging 61, 75-81.

[34] Tijms BM, Yeung HM, Sikkes SA, Moller C, Smits LL, Stam CJ, Scheltens P, van der Flier WM, Barkhof F (2014) Single-subject gray matter graph properties and their relationship with cognitive impairment in early- and late-onset Alzheimer's disease. Brain Connect 4, 337346.

[35] Sluimer JD, van der Flier WM, Karas GB, Fox NC, Scheltens P, Barkhof F, Vrenken H (2008) Whole-brain atrophy rate and cognitive decline: Longitudinal MR study of memory clinic patients. Radiology 248, 590-598.

[36] Bertens D, Knol DL, Scheltens P, Visser PJ, Alzheimer's Disease Neuroimaging Initiative (2015) Temporal evolution of biomarkers and cognitive markers in the asymptomatic, MCI, and dementia stage of Alzheimer's disease. Alzheimers Dement 11, 511-522.

[37] Schoonenboom NS, Pijnenburg YA, Mulder C, Rosso SM, Van Elk EJ, van Kamp GJ, van Swieten JC, Scheltens P (2004) Amyloid beta(1-42) and phosphorylated tau in CSF as markers for early-onset Alzheimer disease. Neurology 62, 1580-1584.

[38] Schoonenboom SN, Visser PJ, Mulder C, Lindeboom J, Van Elk EJ, van Kamp GJ, Scheltens PH (2005) Biomarker profiles and their relation to clinical variables in mild cognitive impairment. Neurocase 11, 8-13.

[39] Blennow K, Hampel H (2003) CSF markers for incipient Alzheimer's disease. Lancet Neurol 2, 605-613.

[40] Mulder C, Verwey NA, van der Flier WM, Bouwman FH, Kok A, Van Elk EJ, Scheltens P, Blankenstein MA (2010) Amyloid-beta(1-42), total tau, and phosphorylated tau as cerebrospinal fluid biomarkers for the diagnosis of Alzheimer disease. Clin Chem 56, 248-253.

[41] Zwan M, van HA, Ossenkoppele R, Bouwman F, Teunissen C, Adriaanse S, Lammertsma A, Scheltens P, Van BB, van der Flier W (2014) Concordance between cerebrospinal fluid biomarkers and [11C]PIB PET in a memory clinic cohort. J Alzheimers Dis 41, 801-807.

[42] Bertens D, Tijms BM, Scheltens P, Teunissen CE, Visser PJ (2017) Unbiased estimates of cerebrospinal fluid betaamyloid 1-42 cutoffs in a large memory clinic population. Alzheimers Res Ther 9, 8.
[43] Duits FH, Teunissen CE, Bouwman FH, Visser PJ, Mattsson N, Zetterberg H, Blennow K, Hansson O, Minthon L, Andreasen N, Marcusson J, Wallin A, Rikkert MO, Tsolaki M, Parnetti L, Herukka SK, Hampel H, de Leon MJ, Schroder J, Aarsland D, Blankenstein MA, Scheltens P, van der Flier WM (2014) The cerebrospinal fluid "Alzheimer profile": Easily said, but what does it mean? Alzheimers. Dement 10, 713-723.

[44] Verwey NA, van der Flier WM, Blennow K, Clark C, Sokolow S, De Deyn PP, Galasko D, Hampel H, Hartmann T, Kapaki E, Lannfelt L, Mehta PD, Parnetti L, Petzold A, Pirttila T, Saleh L, Skinningsrud A, Swieten JC, Verbeek MM, Wiltfang J, Younkin S, Scheltens P, Blankenstein MA (2009) A worldwide multicentre comparison of assays for cerebrospinal fluid biomarkers in Alzheimer's disease. Ann Clin Biochem 46, 235-240.

[45] Engelborghs S, Niemantsverdriet E, Struyfs H, Blennow K, Brouns R, Comabella M, Dujmovic I, van der Flier W, Frolich L, Galimberti D, Gnanapavan S, Hemmer B, Hoff E, Hort J, Iacobaeus E, Ingelsson M, Jan de Jong F, Jonsson M, Khalil M, Kuhle J, Lleo A, de Mendonca A, Molinuevo JL, Nagels G, Paquet C, Parnetti L, Roks G, Rosa-Neto P, Scheltens P, Skarsgard C, Stomrud E, Tumani H, Visser PJ, Wallin A, Winblad B, Zetterberg H, Duits F, Teunissen CE (2017) Consensus guidelines for lumbar puncture in patients with neurological diseases. Alzheimers Dement (Amst) 8, 111-126.

[46] Babapour Mofrad R, Bouwman FH, Slot RER, Timmers T, van der Flier WM, Scheltens P, Teunissen CE (2017) Lumbar puncture in patients with neurologic conditions. Alzheimers Dement (Amst) 8, 108-110.

[47] Bouwman FH, van der Flier WM, Schoonenboom NS, Van Elk EJ, Kok A, Scheltens P, Blankenstein MA (2006) Usefulness of longitudinal measurements of beta-amyloid1-42 in cerebrospinal fluid of patients with various cognitive and neurologic disorders. Clin Chem 52, 1604-1606.

[48] Verwey NA, Bouwman FH, van der Flier WM, Veerhuis R, Scheltens P, Blankenstein MA (2008) Variability in longitudinal cerebrospinal fluid tau and phosphorylated tau measurements. Clin Chem Lab Med 46, 1300-1304.

[49] Bouwman FH, van der Flier WM, Schoonenboom NS, Van Elk EJ, Kok A, Rijmen F, Blankenstein MA, Scheltens $P$ (2007) Longitudinal changes of CSF biomarkers in memory clinic patients. Neurology 69, 1006-1011.

[50] Kester MI, Scheffer PG, Koel-Simmelink MJ, Twaalfhoven H, Verwey NA, Veerhuis R, Twisk JW, Bouwman FH, Blankenstein MA, Scheltens P, Teunissen C, van der Flier WM (2012) Serial CSF sampling in Alzheimer's disease: Specific versus non-specific markers. Neurobiol Aging 33, 1591-1598.

[51] Kester MI, Teunissen CE, Crimmins DL, Herries EM, Ladenson JH, Scheltens P, van der Flier WM, Morris JC, Holtzman DM, Fagan AM (2015) Neurogranin as a cerebrospinal fluid biomarker for synaptic loss in symptomatic Alzheimer disease. JAMA Neurol 72, 1275-1280.

[52] Kester MI, Teunissen CE, Sutphen C, Herries EM, Ladenson JH, Xiong C, Scheltens P, van der Flier WM, Morris JC, Holtzman DM, Fagan AM (2015) Cerebrospinal fluid VILIP-1 and YKL-40, candidate biomarkers to diagnose, predict and monitor Alzheimer's disease in a memory clinic cohort. Alzheimers Res Ther 7, 59.

[53] Kester MI, van der Flier WM, Visser A, Blankenstein MA, Scheltens P, Oudejans CB (2012) Decreased mRNA expression of CCL5 [RANTES] in Alzheimer's disease blood samples. Clin Chem Lab Med 50, 61-65. 
[54] van Harten AC, Mulders J, Scheltens P, van der Flier WM, Oudejans CB (2015) Differential expression of microRNA in cerebrospinal fluid as a potential novel biomarker for Alzheimer's disease. J Alzheimers Dis 47, 243-252.

[55] Teunissen CE, van der Flier WM, Scheltens P, Duits A, Wijnstok N, Nijpels G, Dekker JM, Blankenstein RM, Heijboer AC (2015) Serum leptin is not altered nor related to cognitive decline in Alzheimer's disease. J Alzheimers Dis 44, 809-813.

[56] Kester MI, Verwey NA, Van Elk EJ, Scheltens P, Blankenstein MA (2010) Evaluation of plasma Abeta40 and Abeta42 as predictors of conversion to Alzheimer's disease in patients with mild cognitive impairment. Neurobiol Aging 31, 539-540.

[57] Small GW, Kepe V, Ercoli LM, Siddarth P, Bookheimer SY, Miller KJ, Lavretsky H, Burggren AC, Cole GM, Vinters HV, Thompson PM, Huang SC, Satyamurthy N, Phelps ME, Barrio JR (2006) PET of brain amyloid and tau in mild cognitive impairment. $N$ Engl J Med 355, 2652-2663.

[58] Klunk WE, Engler H, Nordberg A, Wang Y, Blomqvist G, Holt DP, Bergstrom M, Savitcheva I, Huang GF, Estrada S, Ausen B, Debnath ML, Barletta J, Price JC, Sandell J, Lopresti BJ, Wall A, Koivisto P, Antoni G, Mathis CA, Langstrom B (2004) Imaging brain amyloid in Alzheimer's disease with Pittsburgh Compound-B. Ann Neurol 55, 306-319.

[59] Tolboom N, van der Flier WM, Boverhoff J, Yaqub M, Wattjes MP, Raijmakers PG, Barkhof F, Scheltens P, Herholz K, Lammertsma AA, van Berckel BN (2010) Molecular imaging in the diagnosis of Alzheimer's disease: Visual assessment of [11C]PIB and [18F]FDDNP PET images. J Neurol Neurosurg Psychiatry 81, 882-884.

[60] Tolboom N, Yaqub M, van der Flier WM, Boellaard R, Luurtsema G, Windhorst AD, Barkhof F, Scheltens P, Lammertsma AA, van Berckel BN (2009) Detection of Alzheimer pathology in vivo using both 11C-PIB and 18F-FDDNP PET. J Nucl Med 50, 191-197.

[61] Tolboom N, van der Flier WM, Yaqub M, Boellaard R, Verwey NA, Blankenstein MA, Windhorst AD, Scheltens P, Lammertsma AA, van Berckel BN (2009) Relationship of cerebrospinal fluid markers to $11 \mathrm{C}-\mathrm{PiB}$ and $18 \mathrm{~F}-\mathrm{FDDNP}$ binding. J Nucl Med 50, 1464-1470.

[62] Tolboom N, van der Flier WM, Yaqub M, Koene T, Boellaard R, Windhorst AD, Scheltens P, Lammertsma AA, van Berckel BN (2009) Differential association of [11C]PIB and $[18 \mathrm{~F}]$ FDDNP binding with cognitive impairment. Neurology 73, 2079-2085.

[63] van Assema DM, Lubberink M, Bauer M, van der Flier WM, Schuit RC, Windhorst AD, Comans EF, Hoetjes NJ, Tolboom N, Langer O, Muller M, Scheltens P, Lammertsma AA, van Berckel BN (2012) Blood-brain barrier P-glycoprotein function in Alzheimer's disease. Brain 135, 181-189.

[64] Schuitemaker A, Kropholler MA, Boellaard R, van der Flier WM, Kloet RW, van der Doef TF, Knol DL, Windhorst AD, Luurtsema G, Barkhof F, Jonker C, Lammertsma AA, Scheltens P, van Berckel BN (2013) Microglial activation in Alzheimer's disease: An (R)[(1)(1)C]PK11195 positron emission tomography study. Neurobiol Aging 34, 128-136.

[65] Liedorp M, van der Flier WM, Hoogervorst EL, Scheltens P, Stam CJ (2009) Associations between patterns of EEG abnormalities and diagnosis in a large memory clinic cohort. Dement Geriatr Cogn Disord 27, 18-23.
[66] de Waal H, Stam CJ, Blankenstein MA, Pijnenburg YA, Scheltens P, van der Flier WM (2011) EEG abnormalities in early and late onset Alzheimer's disease: Understanding heterogeneity. J Neurol Neurosurg Psychiatry 82, 67-71.

[67] Liedorp M, Stam CJ, van der Flier WM, Pijnenburg YA, Scheltens P (2010) Prevalence and clinical significance of epileptiform EEG discharges in a large memory clinic cohort. Dement Geriatr Cogn Disord 29, 432-437.

[68] dW H, Stam CJ, de HW, Van Straaten EC, Scheltens P, van der Flier WM (2012) Young Alzheimer patients show distinct regional changes of oscillatory brain dynamics. Neurobiol Aging 33, 1008-1031.

[69] Stam CJ, de Haan W, Daffertshofer A, Jones BF, Manshanden I, van Cappellen van Walsum AM, Montez T, Verbunt JP, de Munck JC, van Dijk BW, Berendse HW, Scheltens P (2009) Graph theoretical analysis of magnetoencephalographic functional connectivity in Alzheimer's disease. Brain 132, 213-224.

[70] dH W, van der Flier WM, Koene T, Smits LL, Scheltens P, Stam CJ (2012) Disrupted modular brain dynamics reflect cognitive dysfunction in Alzheimer's disease. Neuroimage 59, 3085-3093.

[71] de Haan W, van der Flier WM, Wang H, Van Mieghem PF, Scheltens P, Stam CJ (2012) Disruption of functional brain networks in Alzheimer's disease: What can we learn from graph spectral analysis of resting-state magnetoencephalography? Brain Connect 2, 45-55.

[72] Engels MM, Hillebrand A, van der Flier WM, Stam CJ, Scheltens P, van Straaten EC (2016) Slowing of hippocampal activity correlates with cognitive decline in early onset Alzheimer's disease. An MEG study with virtual electrodes. Front Hum Neurosci 10, 238.

[73] Engels MMA, Yu M, Stam CJ, Gouw AA, van der Flier WM, Scheltens P, van Straaten ECW, Hillebrand A (2017) Directional information flow in patients with Alzheimer's disease. A source-space resting-state MEG study. Neuroimage Clin 15, 673-681.

[74] Engels MM, Stam CJ, van der Flier WM, Scheltens P, de WH, Van Straaten EC (2015) Declining functional connectivity and changing hub locations in Alzheimer's disease: An EEG study. BMC Neurol 15, 145.

[75] Frisoni GB, Boccardi M, Barkhof F, Blennow K, Cappa S, Chiotis K, Demonet JF, Garibotto V, Giannakopoulos P, Gietl A, Hansson O, Herholz K, Jack CR Jr, Nobili F, Nordberg A, Snyder HM, Ten Kate M, Varrone A, Albanese E, Becker S, Bossuyt P, Carrillo MC, Cerami C, Dubois B, Gallo V, Giacobini E, Gold G, Hurst S, Lonneborg A, Lovblad KO, Mattsson N, Molinuevo JL, Monsch AU, Mosimann U, Padovani A, Picco A, Porteri C, Ratib O, Saint-Aubert L, Scerri C, Scheltens P, Schott JM, Sonni I, Teipel S, Vineis P, Visser PJ, Yasui Y, Winblad B (2017) Strategic roadmap for an early diagnosis of Alzheimer's disease based on biomarkers. Lancet Neurol 16, 661-676.

[76] Duits FH, Prins ND, Lemstra AW, Pijnenburg YA, Bouwman FH, Teunissen CE, Scheltens $P$, van der Flier WM (2015) Diagnostic impact of CSF biomarkers for Alzheimer's disease in a tertiary memory clinic. Alzheimers Dement 11, 523-532.

[77] Ossenkoppele R, Prins ND, Pijnenburg YA, Lemstra AW, van der Flier WM, Adriaanse SF, Windhorst AD, Handels RL, Wolfs CA, Aalten P, Verhey FR, Verbeek MM, van Buchem MA, Hoekstra OS, Lammertsma AA, Scheltens P, van Berckel BN (2013) Impact of molecular imaging 
on the diagnostic process in a memory clinic. Alzheimers Dement 9, 414-421.

[78] Zwan MD, Bouwman FH, Konijnenberg E, van der Flier WM, Lammertsma AA, Verhey FR, Aalten P, van Berckel BN, Scheltens P (2017) Diagnostic impact of $[18 \mathrm{~F}]$ flutemetamol PET in early-onset dementia. Alzheimers Res Ther 9, 2.

[79] Schoonenboom NS, Reesink FE, Verwey NA, Kester MI, Teunissen CE, van de Ven PM, Pijnenburg YA, Blankenstein MA, Rozemuller AJ, Scheltens P, van der Flier WM (2012) Cerebrospinal fluid markers for differential dementia diagnosis in a large memory clinic cohort. Neurology 78, 47-54.

[80] Ten Kate M, Barkhof F, Boccardi M, Visser PJ, Jack CR Jr, Lovblad KO, Frisoni GB, Scheltens P, Geneva. Task Force for the Roadmap of Alzheimer's Biomarkers (2017) Clinical validity of medial temporal atrophy as a biomarker for Alzheimer's disease in the context of a structured 5phase development framework. Neurobiol Aging 52, 167$182 \mathrm{e} 161$.

[81] de Wilde A, van Maurik IS, Kunneman M, Bouwman F, Zwan M, Willemse EA, Biessels GJ, Minkman M, Pel R, Schoonenboom NS, Smets EM, Wattjes MP, Barkhof F, Stephens A, van Lier EJ, Batrla-Utermann R, Scheltens P, Teunissen CE, van Berckel BN, van der Flier WM (2017) Alzheimer's biomarkers in daily practice (ABIDE) project: Rationale and design. Alzheimers Dement (Amst) 6, 143-151.

[82] Kunneman M, Pel R, Bouwman FH, Gillissen F, Schoonenboom N, Claus JJ, Van der Flier WM, Smets EM (2017) Patients' and caregivers' views on conversations and shared decision making in diagnostic testing for Alzheimer's disease: The ABIDE project. Alzheimers Dement (N Y) 3, 314-322.

[83] Kunneman M, Smets EM, Bouwman F, Schoonenboom N, Zwan M, Pel R, Van der Flier WM (2017) Clinicians' views on conversations and shared decision making in diagnostic testing for Alzheimer's disease: The ABIDE project. Alzheimers Dement (N Y) 3, 305-313.

[84] Van der Flier WM, Kunneman M, Bouwman F, Petersen RC, Smets EM (2017) Diagnostic dilemmas in Alzheimer's disease: Room for shared decision making. Alzheimers Dement (N Y) 3, 301-304.

[85] Dubois B, Feldman HH, Jacova C, Hampel H, Molinuevo JL, Blennow K, DeKosky ST, Gauthier S, Selkoe D, Bateman R, Cappa S, Crutch S, Engelborghs S, Frisoni GB, Fox NC, Galasko D, Habert MO, Jicha GA, Nordberg A, Pasquier F, Rabinovici G, Robert P, Rowe C, Salloway S, Sarazin M, Epelbaum S, de Souza LC, Vellas B, Visser PJ, Schneider L, Stern Y, Scheltens P, Cummings JL (2014) Advancing research diagnostic criteria for Alzheimer's disease: The IWG-2 criteria. Lancet Neurol 13, 614-629.

[86] Dubois B, Feldman HH, Jacova C, Cummings JL, DeKosky ST, Barberger-Gateau P, Delacourte A, Frisoni G, Fox NC, Galasko D, Gauthier S, Hampel H, Jicha GA, Meguro K, O’Brien J, Pasquier F, Robert P, Rossor M, Salloway S, Sarazin M, de Souza LC, Stern Y, Visser PJ, Scheltens P (2010) Revising the definition of Alzheimer's disease: A new lexicon. Lancet Neurol 9, 1118-1127.

[87] Dubois B, Feldman HH, Jacova C, DeKosky ST, Barberger-Gateau P, Cummings J, Delacourte A, Galasko D, Gauthier S, Jicha G, Meguro K, O'Brien J, Pasquier F, Robert P, Rossor M, Salloway S, Stern Y, Visser PJ, Scheltens P (2007) Research criteria for the diagnosis of Alzheimer's disease: Revising the NINCDS-ADRDA criteria. Lancet Neurol 6, 734-746.

[88] Sikkes SA, de Lange-de Klerk ES, Pijnenburg YA, Scheltens P, Uitdehaag BM (2009) A systematic review of Instrumental Activities of Daily Living scales in dementia: Room for improvement. J Neurol Neurosurg Psychiatry 80, 7-12.

[89] Sikkes SA, Knol DL, Pijnenburg YA, dL-dK ES, Uitdehaag BM, Scheltens P (2013) Validation of the Amsterdam IADL Questionnaire(c), a new tool to measure instrumental activities of daily living in dementia. Neuroepidemiology 41, 35-41.

[90] Sikkes SA, de Lange-de Klerk ES, Pijnenburg YA, Gillissen F, Romkes R, Knol DL, Uitdehaag BM, Scheltens P (2012) A new informant-based questionnaire for instrumental activities of daily living in dementia. Alzheimers Dement 8, 536-543.

[91] Koster N, Knol DL, Uitdehaag BM, Scheltens P, Sikkes SA (2015) The sensitivity to change over time of the Amsterdam IADL Questionnaire((c)). Alzheimers Dement 11, 1231-1240.

[92] Sikkes SA, Pijnenburg YA, Knol DL, de Lange-de Klerk ES, Scheltens P, Uitdehaag BM (2013) Assessment of instrumental activities of daily living in dementia: Diagnostic value of the Amsterdam Instrumental Activities of Daily Living Questionnaire. J Geriatr Psychiatry Neurol 26, 244-250.

[93] Jutten RJ, Peeters CFW, Leijdesdorff SMJ, Visser PJ, Maier AB, Terwee CB, Scheltens P, Sikkes SAM (2017) Detecting functional decline from normal aging to dementia: Development and validation of a short version of the Amsterdam IADL Questionnaire. Alzheimers Dement (Amst) 8, 26-35.

[94] Sluimer JD, Bouwman FH, Vrenken H, Blankenstein MA, Barkhof F, van der Flier WM, Scheltens P (2010) Wholebrain atrophy rate and CSF biomarker levels in MCI and AD: A longitudinal study. Neurobiol Aging 31, 758-764.

[95] Yi HA, Moller C, Dieleman N, Bouwman FH, Barkhof F, Scheltens P, van der Flier WM, Vrenken H (2016) Relation between subcortical grey matter atrophy and conversion from mild cognitive impairment to Alzheimer's disease. J Neurol Neurosurg Psychiatry 87, 425-432.

[96] Binnewijzend MA, Kuijer JP, Benedictus MR, van der Flier WM, Wink AM, Wattjes MP, van Berckel BN, Scheltens P, Barkhof F (2013) Cerebral blood flow measured with 3D pseudocontinuous arterial spin-labeling MR imaging in Alzheimer disease and mild cognitive impairment: A marker for disease severity. Radiology 267, 221-230.

[97] Bouwman FH, Schoonenboom SN, van der Flier WM, Van Elk EJ, Kok A, Barkhof F, Blankenstein MA, Scheltens P (2007) CSF biomarkers and medial temporal lobe atrophy predict dementia in mild cognitive impairment. Neurobiol Aging 28, 1070-1074.

[98] Rhodius-Meester HF, Koikkalainen J, Mattila J, Teunissen CE, Barkhof F, Lemstra AW, Scheltens P, Lotjonen J, van der Flier WM (2016) Integrating biomarkers for underlying Alzheimer's disease in mild cognitive impairment in daily practice: Comparison of a clinical decision support system with individual biomarkers. J Alzheimers Dis $\mathbf{5 0}$, 261-270.

[99] van Rossum IA, Visser PJ, Knol DL, van der Flier WM, Teunissen CE, Barkhof F, Blankenstein MA, Scheltens P (2012) Injury markers but not amyloid markers are associated with rapid progression from mild cog- 
nitive impairment to dementia in Alzheimer's disease. J Alzheimers Dis 29, 319-327.

[100] van Rossum IA, Vos SJ, Burns L, Knol DL, Scheltens P, Soininen H, Wahlund LO, Hampel H, Tsolaki M, Minthon L, L'italien G, van der Flier WM, Teunissen CE, Blennow K, Barkhof F, Rueckert D, Wolz R, Verhey F, Visser PJ (2012) Injury markers predict time to dementia in subjects with MCI and amyloid pathology. Neurology 79, 18091816.

[101] Van Maurik IS, Zwan M, Tijms B, Bouwman F, Teunissen C, Scheltens P, Wattjes MP, Barkhof F, Berkhof H, Van der Flier WM, Alzheimer's Disease Neuroimaging Initiative (2017) Interpreting biomarker results in individual patients with mild cognitive impairment in the Alzheimer's Biomarkers in Daily Practice (ABIDE) Project. JAMA Neurol 74, 1481-1491.

[102] Ossenkoppele R, Tolboom N, Foster-Dingley JC, Adriaanse SF, Boellaard R, Yaqub M, Windhorst AD, Barkhof F, Lammertsma AA, Scheltens P, van der Flier WM, van Berckel BN (2012) Longitudinal imaging of Alzheimer pathology using [11C]PIB, [18F]FDDNP and [18F]FDG PET. Eur J Nucl Med Mol Imaging 39, 990-1000.

[103] Ossenkoppele R, van der Flier WM, Verfaillie SC, Vrenken H, Versteeg A, van Schijndel RA, Sikkes SA, Twisk J, Adriaanse SM, Zwan MD, Boellaard R, Windhorst AD, Barkhof F, Scheltens P, Lammertsma AA, van Berckel BN (2014) Long-term effects of amyloid, hypometabolism, and atrophy on neuropsychological functions. Neurology 82, 1768-1775.

[104] Jessen F, Amariglio RE, van BM, Breteler M, Ceccaldi M, Chetelat G, Dubois B, Dufouil C, Ellis KA, van der Flier WM, Glodzik L, van Harten AC, de Leon MJ, McHugh P, Mielke MM, Molinuevo JL, Mosconi L, Osorio RS, Perrotin A, Petersen RC, Rabin LA, Rami L, Reisberg B, Rentz DM, Sachdev PS, de IS V, Saykin AJ, Scheltens P, Shulman MB, Slavin MJ, Sperling RA, Stewart R, Uspenskaya O, Vellas B, Visser PJ, Wagner M (2014) A conceptual framework for research on subjective cognitive decline in preclinical Alzheimer's disease. Alzheimers Dement 10, 844-852.

[105] van der Flier WM, Pijnenburg YA, Schoonenboom SN, Dik MG, Blankenstein MA, Scheltens P (2008) Distribution of APOE genotypes in a memory clinic cohort. Dement Geriatr Cogn Disord 25, 433-438.

[106] van Harten AC, Visser PJ, Pijnenburg YA, Teunissen CE, Blankenstein MA, Scheltens P, van der Flier WM (2013) Cerebrospinal fluid Abeta42 is the best predictor of clinical progression in patients with subjective complaints. Alzheimers Dement 9, 481-487.

[107] van Harten AC, Jongbloed W, Teunissen CE, Scheltens P, Veerhuis R, van der Flier WM (2017) CSF ApoE predicts clinical progression in nondemented APOEepsilon4 carriers. Neurobiol Aging 57, 186-194.

[108] Slot RE, Van Harten AC, Kester MI, Jongbloed W, Bouwman FH, Teunissen CE, Scheltens P, Veerhuis R, van der Flier WM (2017) Apolipoprotein A1 in cerebrospinal fluid and plasma and progression to Alzheimer's disease in nondemented elderly. J Alzheimers Dis 56, 687-697.

[109] Benedictus MR, van Harten AC, Leeuwis AE, Koene T, Scheltens P, Barkhof F, Prins ND, van der Flier WM (2015) White matter hyperintensities relate to clinical progression in subjective cognitive decline. Stroke 46, 2661-2664.

[110] Verfaillie SC, Tijms B, Versteeg A, Benedictus MR, Bouwman FH, Scheltens P, Barkhof F, Vrenken H, van der Flier WM (2016) Thinner temporal and parietal cor- tex is related to incident clinical progression to dementia in patients with subjective cognitive decline. Alzheimers Dement (Amst) 5, 43-52.

[111] Gouw AA, Alsema AM, Tijms BM, Borta A, Scheltens P, Stam CJ, van der Flier WM (2017) EEG spectral analysis as a putative early prognostic biomarker in nondemented, amyloid positive subjects. Neurobiol Aging 57, 133-142.

[112] Ossenkoppele R, Pijnenburg YA, Perry DC, Cohn-Sheehy BI, Scheltens NM, Vogel JW, Kramer JH, van der Vlies AE, La JR, Rosen HJ, van der Flier WM, Grinberg LT, Rozemuller AJ, Huang EJ, van Berckel BN, Miller BL, Barkhof F, Jagust WJ, Scheltens P, Seeley WW, Rabinovici GD (2015) The behavioural/dysexecutive variant of Alzheimer's disease: Clinical, neuroimaging and pathological features. Brain 138, 2732-2749.

[113] Crutch SJ, Schott JM, Rabinovici GD, Boeve BF, Cappa SF, Dickerson BC, Dubois B, Graff-Radford NR, KrolakSalmon P, Lehmann M, Mendez MF, Pijnenburg Y, Ryan NS, Scheltens P, Shakespeare T, Tang-Wai DF, van der Flier WM, Bain L, Carrillo MC, Fox NC (2013) Shining a light on posterior cortical atrophy. Alzheimers Dement $\mathbf{9}$, 463-465.

[114] Gorno-Tempini ML, Hillis AE, Weintraub S, Kertesz A, Mendez M, Cappa SF, Ogar JM, Rohrer JD, Black S, Boeve BF, Manes F, Dronkers NF, Vandenberghe R, Rascovsky K, Patterson K, Miller BL, Knopman DS, Hodges JR, Mesulam MM, Grossman M (2011) Classification of primary progressive aphasia and its variants. Neurology 76, 1006-1014.

[115] Koedam EL, Lauffer V, van der Vlies AE, van der Flier WM, Scheltens P, Pijnenburg YA (2010) Early-versus late-onset Alzheimer's disease: More than age alone. J Alzheimers Dis 19, 1401-1408.

[116] Smits LL, Pijnenburg YA, Koedam EL, van der Vlies AE, Reuling IE, Koene T, Teunissen CE, Scheltens P, van der Flier WM (2012) Early onset Alzheimer's disease is associated with a distinct neuropsychological profile. J Alzheimers Dis 30, 101-108.

[117] de Haan W, Stam CJ, de HW, Van Straaten EC, Blankenstein MA, Scheltens P, van der Flier WM (2013) Alzheimer's disease patients not carrying the apolipoprotein E epsilon4 allele show more severe slowing of oscillatory brain activity. Neurobiol Aging 34, 2158-2163.

[118] Smits LL, Liedorp M, Koene T, Roos-Reuling IE, Lemstra AW, Scheltens P, Stam CJ, van der Flier WM (2011) EEG abnormalities are associated with different cognitive profiles in Alzheimer's disease. Dement Geriatr Cogn Disord 31, 1-6.

[119] Ossenkoppele R, Zwan MD, Tolboom N, van Assema DM, Adriaanse SF, Kloet RW, Boellaard R, Windhorst AD, Barkhof F, Lammertsma AA, Scheltens P, van der Flier WM, van Berckel BN (2012) Amyloid burden and metabolic function in early-onset Alzheimer's disease: Parietal lobe involvement. Brain 135, 2115-2125.

[120] Ossenkoppele R, van der Flier WM, Zwan MD, Adriaanse SF, Boellaard R, Windhorst AD, Barkhof F, Lammertsma AA, Scheltens P, van Berckel BN (2013) Differential effect of APOE genotype on amyloid load and glucose metabolism in AD dementia. Neurology 80, 359-365.

[121] van der Flier WM, Pijnenburg YA, Fox NC, Scheltens P (2011) Early-onset versus late-onset Alzheimer's disease: The case of the missing APOE varepsilon4 allele. Lancet Neurol 10, 280-288. 
[122] van der Flier WM, Schoonenboom SN, Pijnenburg YA, Fox NC, Scheltens P (2006) The effect of APOE genotype on clinical phenotype in Alzheimer disease. Neurology 67, 526-527.

[123] Scheltens NM, Galindo-Garre F, Pijnenburg YA, van der Vlies AE, Smits LL, Koene T, Teunissen CE, Barkhof F, Wattjes MP, Scheltens P, van der Flier WM (2016) The identification of cognitive subtypes in Alzheimer's disease dementia using latent class analysis. J Neurol Neurosurg Psychiatry 87, 235-243.

[124] Scheltens NME, Tijms BM, Koene T, Barkhof F, Teunissen CE, Wolfsgruber S, Wagner M, Kornhuber J, Peters O, Cohn-Sheehy BI, Rabinovici GD, Miller BL, Kramer JH, Scheltens P, van der Flier WM, Alzheimer's Disease Neuroimaging Initiative, German Dementia Competence Network, University of California San Francisco Memory and Aging Center, Amsterdam Dementia Cohort (2017) Cognitive subtypes of probable Alzheimer's disease robustly identified in four cohorts. Alzheimers Dement 13, 1226-1236.

[125] Smits LL, Pijnenburg YA, van der Vlies AE, Koedam EL, Bouwman FH, Reuling IE, Scheltens $P$, van der Flier WM (2015) Early onset APOE E4-negative Alzheimer's disease patients show faster cognitive decline on non-memory domains. Eur Neuropsychopharmacol 25, 1010-1017.

[126] van der Vlies AE, Koedam EL, Pijnenburg YA, Twisk JW, Scheltens P, van der Flier WM (2009) Most rapid cognitive decline in APOE epsilon4 negative Alzheimer's disease with early onset. Psychol Med 39, 1907-1911.

[127] Sluimer JD, Vrenken H, Blankenstein MA, Fox NC, Scheltens P, Barkhof F, van der Flier WM (2008) Whole-brain atrophy rate in Alzheimer disease: Identifying fast progressors. Neurology 70, 1836-1841.

[128] Kester MI, van der Vlies AE, Blankenstein MA, Pijnenburg YA, Van Elk EJ, Scheltens P, van der Flier WM (2009) CSF biomarkers predict rate of cognitive decline in Alzheimer disease. Neurology 73, 1353-1358.

[129] Benedictus MR, Leeuwis AE, Binnewijzend MA, Kuijer JP, Scheltens P, Barkhof F, van der Flier WM, Prins ND (2017) Lower cerebral blood flow is associated with faster cognitive decline in Alzheimer's disease. Eur Radiol 27, 1169-1175.

[130] Koedam EL, Pijnenburg YA, Deeg DJ, Baak MM, van der Vlies AE, Scheltens P, van der Flier WM (2008) Earlyonset dementia is associated with higher mortality. Dement Geriatr Cogn Disord 26, 147-152.

[131] Henneman WJ, Sluimer JD, Cordonnier C, Baak MM, Scheltens P, Barkhof F, van der Flier WM (2009) MRI biomarkers of vascular damage and atrophy predicting mortality in a memory clinic population. Stroke 40, 492498.

[132] Staekenborg SS, Pijnenburg YA, Lemstra AW, Scheltens P, Vd Flier WM (2016) Dementia and rapid mortality: Who is at risk? J Alzheimers Dis 53, 135-142.

[133] Krudop WA, Kerssens CJ, Dols A, Prins ND, Moller C, Schouws S, Barkhof F, van Berckel BN, Teunissen CE, van der Flier WM, Scheltens P, Stek ML, Pijnenburg YA (2014) Building a new paradigm for the early recognition of behavioral variant frontotemporal dementia: Late Onset Frontal Lobe Syndrome study. Am J Geriatr Psychiatry 22, 735-740.

[134] Vijverberg EGB, Tijms BM, Dopp J, Hong YJ, Teunissen CE, Barkhof F, Scheltens P, Pijnenburg YAL (2017) Gray matter network differences between behavioral variant frontotemporal dementia and Alzheimer's disease. $\mathrm{Neu}$ robiol Aging 50, 77-86.

[135] Vijverberg EG, Wattjes MP, Dols A, Krudop WA, Moller C, Peters A, Kerssens CJ, Gossink F, Prins ND, Stek ML, Scheltens P, van Berckel BN, Barkhof F, Pijnenburg YA (2016) Diagnostic accuracy of MRI and additional [18F]FDG-PET for behavioral variant frontotemporal dementia in patients with late onset behavioral changes. J Alzheimers Dis 53, 1287-1297.

[136] Vijverberg EG, Dols A, Krudop WA, Del Campo Milan M, Kerssens CJ, Gossink F, Prins ND, Stek ML, Scheltens P, Teunissen CE, Pijnenburg YA (2017) Cerebrospinal fluid biomarker examination as a tool to discriminate behavioral variant frontotemporal dementia from primary psychiatric disorders. Alzheimers Dement (Amst) 7, 99-106.

[137] Roks G, Korf ES, van der Flier WM, Scheltens P, Stam CJ (2008) The use of EEG in the diagnosis of dementia with Lewy bodies. J Neurol Neurosurg Psychiatry 79, 377-380.

[138] McKeith IG, Boeve BF, Dickson DW, Halliday G, Taylor JP, Weintraub D, Aarsland D, Galvin J, Attems J, Ballard CG, Bayston A, Beach TG, Blanc F, Bohnen N, Bonanni L, Bras J, Brundin P, Burn D, Chen-Plotkin A, Duda JE, El-Agnaf O, Feldman H, Ferman TJ, Ffytche D, Fujishiro H, Galasko D, Goldman JG, Gomperts SN, Graff-Radford NR, Honig LS, Iranzo A, Kantarci K, Kaufer D, Kukull W, Lee VMY, Leverenz JB, Lewis S, Lippa C, Lunde A, Masellis M, Masliah E, McLean P, Mollenhauer B, Montine TJ, Moreno E, Mori E, Murray M, O’Brien JT, Orimo S, Postuma RB, Ramaswamy S, Ross OA, Salmon DP, Singleton A, Taylor A, Thomas A, Tiraboschi P, Toledo JB, Trojanowski JQ, Tsuang D, Walker Z, Yamada M, Kosaka K (2017) Diagnosis and management of dementia with Lewy bodies: Fourth consensus report of the DLB Consortium. Neurology 89, 88-100.

[139] McKeith IG (2006) Consensus guidelines for the clinical and pathologic diagnosis of dementia with Lewy bodies (DLB): Report of the Consortium on DLB International Workshop. J Alzheimers Dis 9, 417-423.

[140] Lemstra AW, de Beer MH, Teunissen CE, Schreuder C, Scheltens P, van der Flier WM, Sikkes SA (2017) Concomitant $\mathrm{AD}$ pathology affects clinical manifestation and survival in dementia with Lewy bodies. J Neurol Neurosurg Psychiatry 88, 113-118.

[141] Reesink FE, Lemstra AW, van Dijk KD, Berendse HW, van de Berg WD, Klein M, Blankenstein MA, Scheltens P, Verbeek MM, van der Flier WM (2010) CSF alpha-synuclein does not discriminate dementia with lewy bodies from Alzheimer's disease. J Alzheimers Dis 22, 87-95.

[142] van der Zande JJ, Booij J, Scheltens P, Raijmakers PG, Lemstra AW (2016) [(123)]FP-CIT SPECT scans initially rated as normal became abnormal over time in patients with probable dementia with Lewy bodies. Eur $\mathrm{J}$ Nucl Med Mol Imaging 43, 1060-1066.

[143] Smits LL, van Harten AC, Pijnenburg YA, Koedam EL, Bouwman FH, Sistermans N, Reuling IE, Prins ND, Lemstra AW, Scheltens P, van der Flier WM (2015) Trajectories of cognitive decline in different types of dementia. Psychol Med 45, 1051-1059.

[144] Scheltens P, Barkhof F, Valk J, Algra PR, van der Hoop RG, Nauta J, Wolters EC (1992) White matter lesions on magnetic resonance imaging in clinically diagnosed Alzheimer's disease. Evidence for heterogeneity. Brain 115(Pt 3), 735-748. 
[145] Scheltens P, Barkhof F, Leys D, Pruvo JP, Nauta JJ, Vermersch P, Steinling M, Valk J (1993) A semiquantative rating scale for the assessment of signal hyperintensities on magnetic resonance imaging. J Neurol Sci 114, 7-12.

[146] van der Vlies AE, Staekenborg SS, Admiraal-Behloul F, Prins ND, Barkhof F, Vrenken H, Reiber JH, Scheltens P, van der Flier WM (2013) Associations between magnetic resonance imaging measures and neuropsychological impairment in early and late onset alzheimer's disease. J Alzheimers Dis 35, 169-178.

[147] Cordonnier C, van der Flier WM, Sluimer JD, Leys D, Barkhof F, Scheltens P (2006) Prevalence and severity of microbleeds in a memory clinic setting. Neurology $\mathbf{6 6}$, 1356-1360.

[148] Benedictus MR, Goos JD, Binnewijzend MA, Muller M, Barkhof F, Scheltens P, Prins ND, van der Flier WM (2013) Specific risk factors for microbleeds and white matter hyperintensities in Alzheimer's disease. Neurobiol Aging 34, 2488-2494.

[149] Goos JD, Kester MI, Barkhof F, Klein M, Blankenstein MA, Scheltens P, van der Flier WM (2009) Patients with Alzheimer disease with multiple microbleeds: Relation with cerebrospinal fluid biomarkers and cognition. Stroke 40, 3455-3460.

[150] Goos JD, Teunissen CE, Veerhuis R, Verwey NA, Barkhof F, Blankenstein MA, Scheltens P, van der Flier WM (2012) Microbleeds relate to altered amyloid-beta metabolism in Alzheimer's disease. Neurobiol Aging 33, 1011-1019.

[151] Kester MI, Goos JD, Teunissen CE, Benedictus MR, Bouwman FH, Wattjes MP, Barkhof F, Scheltens P, van der Flier WM (2014) Associations between cerebral small-vessel disease and Alzheimer disease pathology as measured by cerebrospinal fluid biomarkers. JAMA Neurol 71, 855-862.
[152] Benedictus MR, Prins ND, Goos JD, Scheltens P, Barkhof F, van der Flier WM (2015) Microbleeds, mortality, and stroke in Alzheimer disease: The MISTRAL Study. JAMA Neurol 72, 539-545.

[153] van der Vlies AE, Goos JD, Barkhof F, Scheltens P, van der Flier WM (2012) Microbleeds do not affect rate of cognitive decline in Alzheimer disease. Neurology 79, 763-769.

[154] Goos JD, Henneman WJ, Sluimer JD, Vrenken H, Sluimer IC, Barkhof F, Blankenstein MA, Scheltens PH, van der Flier WM (2010) Incidence of cerebral microbleeds: A longitudinal study in a memory clinic population. Neurology 74, 1954-1960.

[155] Leeuwis AE, Benedictus MR, Kuijer JP, Binnewijzend MA, Hooghiemstra AM, Verfaillie SC, Koene T, Scheltens P, Barkhof F, Prins ND, van der Flier WM (2017) Lower cerebral blood flow is associated with impairment in multiple cognitive domains in Alzheimer's disease. Alzheimers Dement 13, 531-540.

[156] Benedictus MR, Binnewijzend MA, Kuijer JP, Steenwijk MD, Versteeg A, Vrenken H, Scheltens P, Barkhof F, van der Flier WM, Prins ND (2014) Brain volume and white matter hyperintensities as determinants of cerebral blood flow in Alzheimer's disease. Neurobiol Aging 35, 26652670 .

[157] Leeuwis AE, Hooghiemstra AM, Amier R, Ferro DA, Franken L, Nijveldt R, Kuijer JP, Bronzwaer AS, van Lieshout J, Rietberg M, Veerbeek JM, Huijsmans RJ, Backx F, Teunissen C, Bron EE, Barkhof F, Prins ND, Shahzad R, Niessen WJ, de Roos A, Van Osch MJ, Van Rossum AC, Biessels GJ, Van der Flier W (2017) Design of the ExCersion-VCI study: The effect of aerobic exercise on cerebral perfusion in patients with vascular cognitive impairment. Alzheimers Dement (N Y) 3, 157-165. 